\title{
Estadísticas poblacionales: marco jurídico, violación de derechos humanos, entorno gubernamental. Dos experiencias, una lectura
}

\author{
Population statistics: legal frameworks, human rights abuse, \\ governmental environment. Two experiences, one lecture
}

\author{
Viviana Masciadri
}

\author{
Centro de Investigaciones y Estudios sobre Cultura y Sociedad/Consejo \\ Nacional de Investigaciones Cientificas y Técnicas (CONICET)/Universidad \\ Nacional de Córdoba
}

\section{Resumen}

Esta investigación compara los marcos jurídicos y el entorno del sistema estadístico argentino y el registro de población israelí delineando, el alcance de la interrelación entre la informática y el uso potencial de datos recabados con fines estadísticos en la planificación de genocidios u otro tipo de atrocidades masivas de población, que comportan políticas demográficas que justifican la violación de la confidencialidad de datos personales con fines de segregación.

Palabras clave: Argentina, Israel, gubernamentabilidad, sistemas estadísticos, registro de población, informática, genocidio, des-civilización.

\section{Abstract}

This research compares the legal frameworks and environment of the Argentine statistical system and the Israeli population registry outlining, the scope of the interrelationship between computer science and the potential use of data collected for statistical purposes in the planning of genocides or other types of mass population atrocities, which involve demographic policies that justify the violation of data confidentiality for segregation purposes.

Key words: Argentina, Israel, gubernamentability, statistical systems, population registry, computer science, genocide, de-civilization. 


\section{INTRODUCCIÓN}

$\mathbf{E}$

sta investigación se propone realizar un análisis comparado entre dos países con experiencias disimiles en ciertos tópicos históricos y normativos asociados con la confidencialidad de los datos amparados mediante leyes de estadística, a lo que se agregan algunos elementos concomitantes al entorno relacionados con historia de la informática.

Para introducir los discutibles fines asociados a las estrategias del poder que justifican, la planificación de destrucciones masivas de población apelando a criterios poblacionistas, maltusianos, natalistas, inmigración selectiva, aborto selectivo por sexo u otro criterio de segregación (Gonnard, 1969; Bongaarts y Greenhalgh, 1985; Foucault, 1992; Kligman, 1998; Vetta y Courgeau, 2003; Domingo, 2008; Greenhalgh, 2008; Feng, Cai y Gu, 2013) es menester revisar, el rol que cumplieron los Estados en torno a la segregación de personas mediante la técnica informática denominada investigación operativa (Borches y Carnota, 2011; Black, 2001). Dicho de otro modo, conocer los casos en que los países manipularon datos poblacionales sin anonimizar para planificar genocidios, exterminios masivos, deportaciones u otras medidas extremas permite introducir, aspectos generales sobre el alcance de la informática en la configuración del mundo actual que determina el rol potencial que tienen los sistemas estadísticos en la planificación de destrucciones masivas de población utilizando datos sensible para la identificación, confiscación, arresto, encarcelamiento, expulsión y, en última instancia, sustracción de las personas clasificadas como tales. Es significativo notar que la programación de dichos delitos requiere de profesionales expertos y de burocracias administrativas aliadas económica e ideológicamente, a las empresas especializadas en la ciencia de datos según aconteció con IBM (Black, 2001).

A propósito, las investigaciones de William Seltzer (1998) y Margo Anderson (2001) publicadas por la Population and Development Review y la Social Research resultan ineludibles pues abordan el protagonismo de Alemania (1933-1945), Polonia (1939-1943), Francia (1940-1944), Países Bajos (1940-1944), Noruega (1942-1944) y Rumania (1941-1943) en la que utilizaron datos de numerosos registros, censos, censos especiales y registros de población múltiples para la planificación de la Shoá. ${ }^{1}$ También se conoce el uso de macro, meso y microdatos de censos especiales, registros

${ }^{1}$ De acuerdo con el demógrafo Sergio Della Pérgola (2016) para el estudio científico del exterminio del pueblo judío perpetrado durante la Segunda Guerra Mundial el termino Shoá — palabra hebrea de género femenino - es más apropiado que el término Holocausto. Se estima que, en 
de población y del Censo de 1940 para planificar y ejecutar desplazamientos territoriales forzados de nativos americanos (fines del siglo XIX) y de japoneses americanos (1941-1945) en Estados Unidos.

Asimismo, las investigaciones de Daniel Feierstein $(2014,2016)$ dan cuenta de que la Unión Soviética (1919-1939) utilizó microdatos y macrodatos de varios censos para reorganizar la población de la república de naciones federadas, con la proclamación de la Unión de Repúblicas Socialistas Soviéticas hacia 1922, extendiendo la burocracia estatal y partidaria en el territorio mediante el desplazamiento por completo o por partes de poblaciones según nacionalidad. Y el colonialismo francés utilizó un censo realizado en 1957 a fin de numerar las viviendas y sus habitantes, un procedimiento usual que luego se empleó para vigilar a diario a la población censada. Además, el estado ruandés al emprender el genocidio tutsi en abril de 1994 empleó estadísticas vitales y de movilidad espacial sin anonimizar en el plan y la logística genocida en tanto práctica social: estadísticas mensuales, listados de nacimientos, defunciones, matrimonios y movilidad en el área y fuera de ella, junto a listas anuales de población, todo clasificado por etnia, fueron entregadas a Préfecture.

En términos de políticas poblacionales ${ }^{2}$ mientras el natalismo procuraría explicar el descenso de la fecundidad, el maltusianismo bregaría por el control del crecimiento poblacional y la eugenesia requeriría intervenir en su composición convirtiendo la fecundidad, la nupcialidad y las migraciones diferenciales en sus centros de interés. Algunas de estas políticas poblacionales fueron sostenidas por periodos prolongados tanto por regímenes autoritarios como el nacionalsocialismo alemán (1933-1945) como por gobiernos democráticos europeos ${ }^{3}$ que instituyeron, la esterilización selectiva de enfermos mentales, alcohólicos, autores de crímenes, "personas irresponsables" u otras medidas eugenésicas para limitar las "clases" inferiores o peligrosas (Domingo, 2008: 28-37).

1939, la población judía mundial rondaba los 16.5 millones, siendo reducida a 11 millones hacia 1945 aunque proyecciones demográficas indican perdidas mayores.

${ }_{2}$ Por política de la población se entiende el conjunto de principios, explícitos o implícitos, que orientan la acción de los poderes públicos en materia de población, o en otras relacionadas con ella. Una política es poblacionista cuando favorece el crecimiento de la población y maltusiana cuando pretende frenar ese crecimiento. Reciben el calificativo de natalistas o de antinatalistas las políticas que tienden, respectivamente, a aumentar o disminuir la natalidad. Las políticas eugenésicas aspiran a mejorar la calidad de la población mediante la multiplicación de los individuos capaces de transmitir caracteres considerados como ventajosos para la especie, impidiendo la reproducción de individuos con caracteres considerados perjudiciales para la especie (Demopædia, s./f.); varios de dichos caracteres son identificados por censos o encuestas existiendo la falacia científica sobre su medición (Vetta y Courgeau, 2003).

${ }^{3}$ Hacia 1934-1935 y hasta: 1957 en Suecia; hasta 1960 en Dinamarca; hasta 1970 en Finlandia; hasta 1974 en Noruega. 
De modo que mediante el análisis comparado de las leyes de estadística y del entorno se logra advertir los fines de segregación de datos nominales con criterios natalistas, maltusianos, eugenistas u otro criterio gubernamental prefijado. Un factor complejo que amerita atención, a la hora de brindar garantías de no repetición en lo atinente a la prevención y sanción de genocidios u otro tipo de atrocidades masivas que comportan políticas segregacionistas sobre la base de datos poblacionales, con el propósito de favorecer la reproducción biológica y social de ciertas poblaciones, obstaculizando o prohibiendo la de otras.

La investigación se expone de la siguiente manera. El primer apartado se denomina Dato-no dato: convenciones y gubernamentabilidad. El segundo Entorno y ley de estadística: experiencia argentina. Y el tercero Entorno y registro de la población: experiencia israelí. Una conclusión a modo de reflexión ubica el tema de los censos y los registros poblacionales en una perspectiva de largo plazo vinculada con el proceso de civilización y tecnificación.

\section{DATO-NO DATO: CONVENCIONES Y GUBERNAMENTABILIDAD}

Para interpretar ciertos aspectos de la gubernamentabilidad es ineludible realizar estudios comparados sin perder de vista la perspectiva de largo plazo. Se entiende por gubernamentabilidad al conjunto de instituciones, cálculos y tácticas que permiten al poder tomar a la población como objetivo principal de su ejercicio, que tiene como forma de saber predominante la economía política y por instrumento técnico los dispositivos de seguridad (Domingo, 2008: 11).

En tal sentido tanto los registros como los censos ${ }^{4}$ son instrumentos para el cálculo de las poblaciones que observados en el largo plazo dejan ver aspectos relativos a los procesos de tecnificación y de civilización en torno al uso de las computadoras. Asimismo, no hay que soslayar que los usos de las herramientas demográficas (censos, registros, etc.) son reguladas a través de las leyes de estadística que tampoco son atemporales.

Por ello los aspectos generales sobre datos, fuentes, tipos de segregación y protección de derechos vinculados a los registros de población y a los censos de población (Esquema 1) se contrastan con las bases de datos de la colección de tratados de Naciones Unidas, capítulo IV sobre Derechos Humanos que ubica en primer término a la Convención para la Prevención y la Sanción del Delito de Genocidio (París, 9/12/1948) y en decimosex-

${ }^{4}$ Mediante una lectura sociológica de los procesos se logra ver que, en ciertos estados, las prácticas censales se convierten en prácticas sociales genocidas (Feierstein, 2014: 33). 
to lugar a la Convención Internacional para la Protección de todas las Personas contra la Desaparición Forzada (CED) (New York, 20/12/2006) advirtiéndose que la ratificación no es necesariamente efectiva, aunque intenta prevenir los delitos aludidos mediante el derecho internacional.

El Esquema 1 recorta las variables vulnerables según tipos de segregación lo que podría coadyuvar a que los controladores - cámaras y poder ejecutivo - de cada país adviertan la necesidad de actualización de los marcos legales vigentes para prevenir el ejercicio abusivo de su poder mediante criterios poblacionistas, maltusianos, natalistas, inmigración selectiva, aborto selectivo por sexo u otro criterio de segregación demográfica gubernamental prefijado sobre todo en periodos autoritarios, aunque también en contextos democráticos pues la mayoría de las naciones del mundo cuentan con el recurso legal que les permite declarar el estado de excepción u otras intervenciones estatales similares.

No hay que eludir que la Convención para la Prevención y la Sanción del Delito de Genocidio entró en vigor el 12 de enero de 1951 habiendo sido ratificada hasta el momento por 40 países que se pueden agrupar según décadas: en la de 1940 firmaron cinco países, en la de 1950 veintiocho países, en la de 1960 dos países, en la de 1970 un país, durante la década de 1980 dos países y en los dos mil dos países más (Tabla 1).

Pese a la existencia de tal Convención entre los estados que no participan se cuentan en Europa: Chipre, Letonia, Moldovia y la Santa Sede y en América central insular: Granada, Guyana, Santa Lucía, Suriname y San Cristóbal y Nieves. Los países del continente africano que no han firmado la Convención son once (Angola, Chad, Eritrea, Guinea Ecuatorial, Kenia, Madagascar, Mauritania, Niger, Madagascar, Mozambique, República Centroafricana y República Unida de Tanzania). Y los pertenecientes al continente asiático llegan a dieciocho (Brunei, Filipinas, Indonesia, Islas Cook, Islas Marshall, Islas Salomón, Japón, Mauritania, Estados Federados de Micronesia, Nieue, Palaos, Reino de Bután, Reino de Tailandia, República de Kiribati, República de Vanuatu, Timor Oriental, Tuvalu y Samoa). Además de Qatar y Omán que se encuentran entre los países del Oriente Medio en tal situación.

Es pertinente mencionar que el término "genocidio" fue creado por Raphael Lemkim y pese a su definición problemática, la Convención en términos jurídicos aplica aun cuando existen tres elementos clave de divergencia en ella: la cuestión de la intencionalidad, el carácter de los grupos incluidos en la definición y el grado de aniquilamiento (total o parcial) como elemento excluyente de la definición (Feierstein, 2014: 33). 
Esquema 1: Datos poblacionales, fuentes, base de la segregación y protección de derechos

\begin{tabular}{|c|c|c|c|}
\hline Datos poblacionales & Fuentes & Segregación basada en & $\begin{array}{c}\text { Protección de derechos } \\
\text { (leyes) }\end{array}$ \\
\hline Sexo, género & Censos & Nociones eugenistas & $\begin{array}{l}\text { Igualdad civil } \\
\text { de las mujeres }\end{array}$ \\
\hline Mujer & Historias clínicas & Estereotipos y prejuicios & Identidad de género \\
\hline Varón & Registro civil & Patologización & $\begin{array}{l}\text { Prevención y sanción } \\
\text { de la violencia } \\
\text { de género }\end{array}$ \\
\hline \multirow[t]{3}{*}{ No binario } & Estadísticas vitales & Justificaciones religiosas & $\begin{array}{l}\text { Femicidio o } \\
\text { feminicidio }\end{array}$ \\
\hline & $\begin{array}{l}\text { Registros de } \\
\text { población }\end{array}$ & Minoría & $\begin{array}{l}\text { Prevención de la discri- } \\
\text { minación, la xenofobia } \\
\text { y el racismo }\end{array}$ \\
\hline & Otros & $\begin{array}{l}\text { Contexto político } \\
\text { (ideología) }\end{array}$ & Otras \\
\hline \multirow{6}{*}{$\begin{array}{l}\text { Morbilidad atendida: } \\
\text { algunas } \\
\text { enfermedades } \\
\text { de la CIE }\end{array}$} & Historias clínicas & Nociones eugenistas & $\begin{array}{l}\text { Salud pública y salud } \\
\text { mental }\end{array}$ \\
\hline & Censos especiales & Patologización & Protección social \\
\hline & & Estereotipos y prejuicios & $\begin{array}{l}\text { Protección específica } \\
\text { según enfermedad, } \\
\text { edad, género, }\end{array}$ \\
\hline & & Justificaciones religiosas & discapacidad \\
\hline & & $\begin{array}{l}\text { Contexto político (ideo- } \\
\text { logía) }\end{array}$ & $\begin{array}{l}\text { Prevención de la } \\
\text { discriminación, } \\
\text { la xenofobia y el } \\
\text { racismo }\end{array}$ \\
\hline & & & Otras \\
\hline \multirow{6}{*}{$\begin{array}{l}\text { Estado personal, civil } \\
\text { o conyugal: soltero, } \\
\text { casado, unido, } \\
\text { divorciado, viudo }\end{array}$} & Censos & Nociones eugenistas & $\begin{array}{l}\text { Matrimonio sin } \\
\text { distinción de culto }\end{array}$ \\
\hline & Registro civil & Justificaciones religiosas & Uniones convicenciales \\
\hline & Estadísticas vitales & Estereotipos y prejuicios & Matrimonio igualitario \\
\hline & & Justificaciones religiosas & Divorcio \\
\hline & & $\begin{array}{l}\text { Contexto político } \\
\text { (ideología) }\end{array}$ & $\begin{array}{l}\text { Protección a la niñez, } \\
\text { adopción y a todo tipo } \\
\text { de familias }\end{array}$ \\
\hline & & Minoría & \\
\hline
\end{tabular}


Estadísticas poblacionales: marco jurídico, violación de derechos humanos, entorno gubernamental ... / V. MASCIADRI

Esquema 1: Continuación

\begin{tabular}{|c|c|c|c|}
\hline Datos poblacionales & Fuentes & Segregación basada en & $\begin{array}{l}\text { Protección de derechos } \\
\text { (leyes) }\end{array}$ \\
\hline \multirow[t]{7}{*}{ Nacionalidad } & Censos & Nociones eugenistas & Migración forzada \\
\hline & Historias clínicas & $\begin{array}{l}\text { Estereotipos y } \\
\text { prejuicios }\end{array}$ & Asilo, refugio \\
\hline & Registro civil & $\begin{array}{l}\text { Justificaciones } \\
\text { religiosas }\end{array}$ & Retorno \\
\hline & Estadísticas vitales & $\begin{array}{l}\text { Contexto político } \\
\text { (ideología) }\end{array}$ & $\begin{array}{l}\text { Prevención y punición } \\
\text { del crimen de genocidio }\end{array}$ \\
\hline & $\begin{array}{l}\text { Registros de } \\
\text { población }\end{array}$ & Minoría & $\begin{array}{l}\text { Crímenes contra la hu- } \\
\text { manidad }\end{array}$ \\
\hline & Censos especiales & & $\begin{array}{l}\text { Prevención de la discri- } \\
\text { minación, la xenofobia } \\
\text { y el racismo }\end{array}$ \\
\hline & Encuestas, otros & & Otras \\
\hline $\begin{array}{l}\text { Etnia, color } \\
\text { de la piel }\end{array}$ & Censos & Racismo blanco o negro & $\begin{array}{l}\text { Prevención y punición } \\
\text { del crimen de genocidio }\end{array}$ \\
\hline \multirow[t]{5}{*}{ Lengua } & $\begin{array}{l}\text { Registros de } \\
\text { población }\end{array}$ & Nociones eugenistas & $\begin{array}{l}\text { Crímenes contra } \\
\text { la humanidad }\end{array}$ \\
\hline & Censos especiales & $\begin{array}{l}\text { Estereotipos y } \\
\text { prejuicios }\end{array}$ & $\begin{array}{l}\text { Prevención de la discri- } \\
\text { minación, la xenofobia } \\
\text { y el racismo }\end{array}$ \\
\hline & Otros & $\begin{array}{l}\text { Justificaciones } \\
\text { religiosas }\end{array}$ & Migración forzada \\
\hline & & $\begin{array}{l}\text { Contexto político } \\
\text { (ideología) }\end{array}$ & Asilo, refugio \\
\hline & & Minoría & Retorno, otras \\
\hline \multirow[t]{5}{*}{ Religión } & Censos & $\begin{array}{l}\text { Justificaciones } \\
\text { religiosas }\end{array}$ & $\begin{array}{l}\text { Prevención y punición } \\
\text { del crimen } \\
\text { de genocidio }\end{array}$ \\
\hline & Registro civil & $\begin{array}{l}\text { Estereotipos y } \\
\text { prejuicios }\end{array}$ & $\begin{array}{l}\text { Crímenes contra la } \\
\text { humanidad }\end{array}$ \\
\hline & $\begin{array}{l}\text { Registros de } \\
\text { población }\end{array}$ & Minoría & $\begin{array}{l}\text { Prevención de la } \\
\text { discriminación, } \\
\text { la xenofobia y el racismo }\end{array}$ \\
\hline & Censos especiales & $\begin{array}{l}\text { Contexto político } \\
\text { (ideología) }\end{array}$ & $\begin{array}{l}\text { Migración forzada, asilo, } \\
\text { refugio, retorno }\end{array}$ \\
\hline & Otros & & Otras \\
\hline
\end{tabular}


Esquema 1: Continuación

\begin{tabular}{|c|c|c|c|}
\hline Datos poblacionales & Fuentes & Segregación basada en & $\begin{array}{c}\text { Protección de derechos } \\
\text { (leyes) }\end{array}$ \\
\hline \multirow[t]{3}{*}{ Educación } & Censos especiales & Estereotipos y prejuicios & Leyes específicas \\
\hline & Registros educación & $\begin{array}{l}\text { Contexto político (ideo- } \\
\text { logía) }\end{array}$ & $\begin{array}{l}\text { Prevención de la discri- } \\
\text { minación, la xenofobia } \\
\text { y el racismo }\end{array}$ \\
\hline & & Minorías & $\begin{array}{l}\text { Protección específica } \\
\text { (enfermedad, edad, } \\
\text { sexo, discapacidad) }\end{array}$ \\
\hline Ocupación: & Censos & Estereotipos y prejuicios & Laborales específicas \\
\hline Ciertas ocupaciones & Registros laborales & $\begin{array}{l}\text { Contexto político (ideo- } \\
\text { logía) }\end{array}$ & $\begin{array}{l}\text { Prevención de la discri- } \\
\text { minación, la xenofobia } \\
\text { y el racismo }\end{array}$ \\
\hline \multirow[t]{2}{*}{ de la CIO } & Censos especiales & Minoría & $\begin{array}{l}\text { Crímenes contra la } \\
\text { humanidad }\end{array}$ \\
\hline & & Minoría & Otras \\
\hline Lugar de residencia & Registros múltiples & Residencial & $\begin{array}{l}\text { Planificación territorial } \\
\text { (saneamiento, alumbra- } \\
\text { do, otras) }\end{array}$ \\
\hline
\end{tabular}

Nota: CIE (Clasificación Internacional de Enfermedades, disponible en línea en la dirección: https:// icd.who.int/es/);

CIUO (la Clasificación Internacional Uniforme de Ocupaciones es una de las principales herramientas estadísticas vinculada a otras clasificaciones económicas y sociales, disponible en línea en la dirección: https://www.ilo.org/public/spanish/bureau/stat/isco/index.htm).

La Organización Internacional del Trabajo (OIT) fue creada en 1919, como parte del Tratado de Versalles que terminó con la Primera Guerra Mundial; Argentina es miembro desde el 28 de junio de 1919.

Fuente: elaboración propia. 
Estadísticas poblacionales: marco jurídico, violación de derechos humanos, entorno gubernamental ... / V. MASCIADRI

Tabla 1: Países que firmaron y adhirieron o ratificaron la Convención para la Prevención y la Sanción de Crímenes de Genocidio agrupados según décadas, 1948-2005

\begin{tabular}{|c|c|c|}
\hline 1940 & 1950 & 1960 \\
\hline 1. Etiopía (1 Jul 1949) & 1. Panamá (11 Jan 1950) & 1. Perú (24 Feb 1960) \\
\hline 2. Australia (8 Jul 1949) & 2. Guatemala (13 Jan 1950) & 2. Uruguay (11 Jul 1967) \\
\hline 3. Noruega (22 Jul 1949) & 3. Israel (9 Mar 1950) & 1970 \\
\hline 4. Islandia (29 Aug 1949) & 4. Liberia (20 Jun 1950) & 1. Nueva Zelanda (28 Dec 1978$)$ \\
\hline \multirow[t]{24}{*}{ 5. Ecuador (21 Dec 1949) } & 5. Filipinas (7 Jul 1950) & 1980 \\
\hline & 6. El Salvador (28 Sep 1950) & 1. China (18 Apr 1983) \\
\hline & 7. Haití (14 Oct 1950) & $\begin{array}{l}\text { 2. Estados Unidos } \\
\text { de América ( } 25 \text { Nov 1988) }\end{array}$ \\
\hline & 8. Francia (14 Oct 1950) & 2000 \\
\hline & 9. Dinamarca (15 Jun 1951) & 1. Paraguay ( 3 Oct 2001) \\
\hline & 10. Bélgica (5 Sep 1951) & 2. Bolivia (14 Jun 2005) \\
\hline & 11. Egipto (8 Feb 1952) & \\
\hline & 12. Honduras (5 Mar 1952) & \\
\hline & 13. Brasil (15 Apr 1952) & \\
\hline & 14. Suecia (27 May 1952) & \\
\hline & 15. México (22 Jul 1952) & \\
\hline & 16. Canadá (3 Sep 1952) & \\
\hline & 17. Cuba (4 Mar 1953) & \\
\hline & 18. Chile ( 3 Jun 1953) & \\
\hline & 19. Líbano (17 Dec 1953) & \\
\hline & $\begin{array}{l}\text { 20. Federación Rusa ( } 3 \text { May } \\
\text { 1954) }\end{array}$ & \\
\hline & 21. Bielorrusia (11 Aug 1954) & \\
\hline & 22. Ucrania (15 Nov 1954) & \\
\hline & 23. Grecia (8 Dec 1954) & \\
\hline & 24. Myanmar (14 Mar 1956) & \\
\hline & 25. Irán (14 Aug 1956) & \\
\hline & 26. India (27 Aug 1959) & \\
\hline & 27. Pakistán (12 Oct 1957) & \\
\hline & 28. Colombia (27 Oct 1959) & \\
\hline
\end{tabular}

Fuente: https://treaties.un.org/Pages/ViewDetails.aspx?src=TREATY\&mtdsg_no=IV-1\&chapter $=4 \&$ clang $=$ en 
Con todo, en la experiencia argentina al menos diecisiete sentencias (2014-2019) califican al genocidio reorganizador argentino como tal (Tabla 1 y Anexo 1).

Sobre la Convención Internacional para la Protección de todas las Personas contra la Desaparición Forzada (CED) adoptada por la Asamblea General de Naciones Unidas el 20 de diciembre de 2006, la norma entró en vigor cuatro años después, el 20 de diciembre de 2010 con una totalidad de 98 estados signatarios y 63 partes $^{5}$ (Tabla 2 ).

Un concepto clave en dicha Convención radica en la prohibición de justificar la desaparición forzada en estado de guerra, estado de excepción, razones de seguridad nacional, inestabilidad política o emergencia pública.

$\mathrm{Al}$ respecto, se conoce que en la situación actual por la pandemia del Covid-19, la Cepal (2020) ha señalado la prioridad de la protección de datos personales "ya que la seguridad de la infraestructura digital (por ejemplo, la prevención de la piratería informática de los centros de salud)" hoy puede ser entendida como una temática de vida o muerte, aunque se desconoce si además de los registros de morbimortalidad, las rondas censales de 2020 incluirán preguntas sobre Covid-19 u otros temas sensibles como el documento nacional de identidad (Arriola et al., 2018; Grushka, 2019; INDEC, 2020; Clarín, 2020). ${ }^{6}$

\footnotetext{
${ }^{5}$ La Declaración sobre la Protección de Todas las Personas contra las Desapariciones Forzadas fue adoptada por la Asamblea General de las Naciones Unidas el 18/12/1992.

${ }^{6}$ Argentina ha recibido un préstamo del Banco Interamericano de Desarrollo para cumplir con el Programa de Fortalecimiento de la Capacidad Estadística del INDEC que se propone destinar parte del préstamo a la ejecución del Censo Experimental 2020 y el Censo Nacional de Población, Hogares y Viviendas. Por ello, el 22/7/2020 se realizó el acto de apertura de las expresiones de interés de TNGROUP S.A./INDRA S.A.; GC Gestión Compartida S.A./Oportunidades S.A.; BOLDT Impresores S.A.; Sociedad del Estado CASA DE MONEDA; SMARTMATIC INTERNATIONAL HOLDING BV Sucursal Argentina/CENTRO NACIONAL DE CONSULTORÍA S.A. En las presentaciones, TNG Indra y GC Digital aludieron explícitamente al secreto estadístico, a la anonimizarían de datos personales o a la confidencialidad — protección de información sensibles o privada de accesos no autorizados-- en cambio, SMARTMATIC presentó un modelo Omnicanal con inconsistencias metodológicas y en la confidencialidad (INDEC, 2020).
} 
Estadísticas poblacionales: marco jurídico, violación de derechos humanos, entorno gubernamental ... / V. MASCIADRI

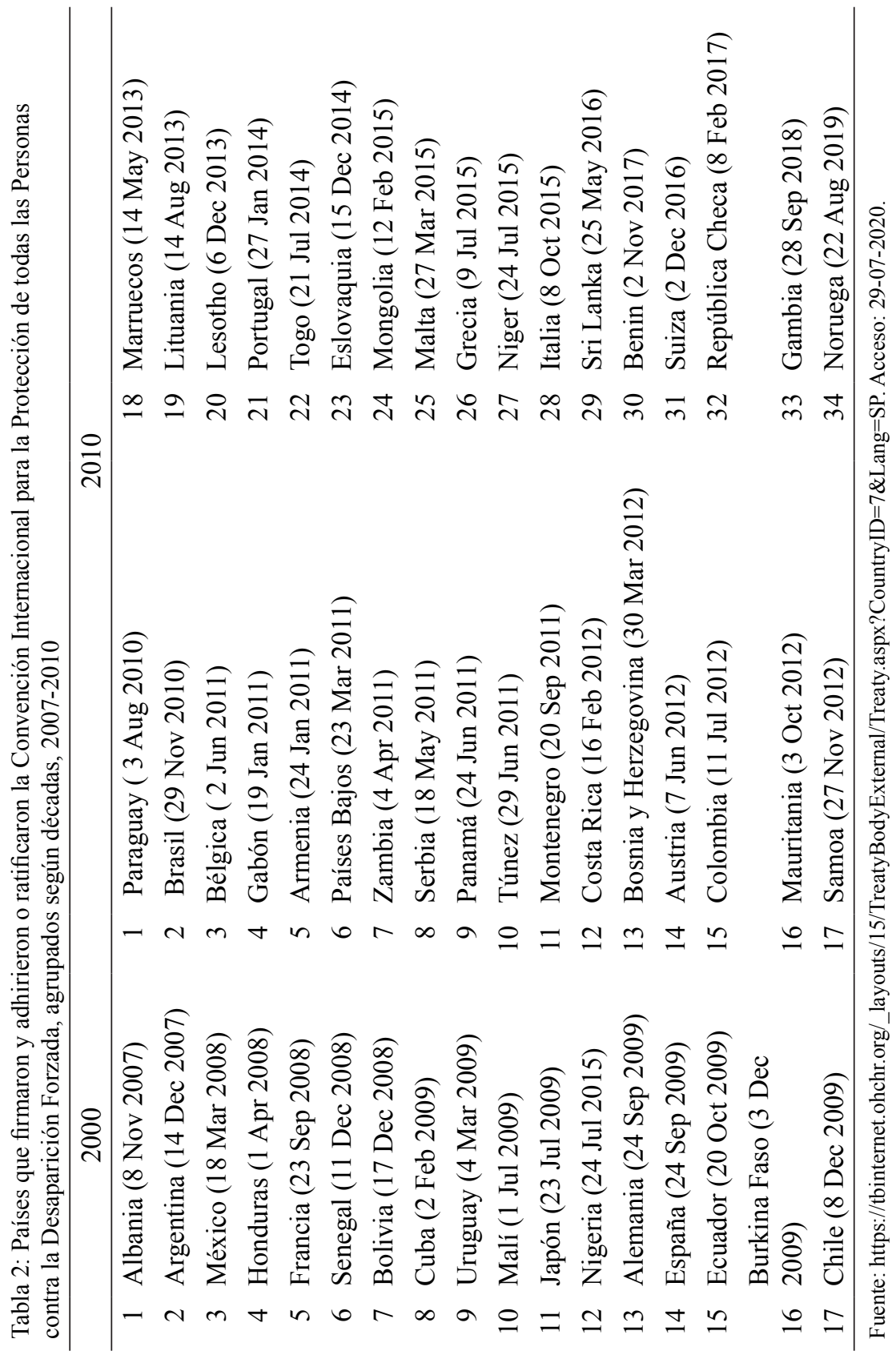


Tanto es así que en la situación actual de la pandemia por el coronavirus varios países europeos dudan de la conveniencia de confiar el despliegue de las redes de telecomunicaciones 5G a la empresa Huawei, "por ser «un proveedor de alto riesgo» para la seguridad nacional" alertando acerca de la dependencia excesiva de China. Un razonamiento que se reafirma ante la promulgación de la controvertida ley de seguridad de Hong Kong que criminaliza la secesión, subversión y colusión con fuerzas extranjeras, y restringe el derecho a las protestas y la libertad de expresión lo que generó tensiones diplomáticas con Estados Unidos, la Unión Europea (UE) y el Reino Unido.

Se conoce que en China "dos de los ocho médicos de Wuhan que, en diciembre de 2019, alertaron sobre la gravedad del coronavirus y fueron hostigados y arrestados por ello, fallecieron en febrero y marzo" y se desconoce el paradero de los seis médicos restantes (Tang, 2019; Cardenal, 2020; Télam, 2020). Asimismo, en octubre de 2020, el presidente de China alentó a su ejército a que se prepare para la contienda (Ámbito, 2020(b); Nakamae, 2020; Rubiolo, 2021) lanzando además un censo que georreferenció toda la información incrementando aún más, el control cibernético de la población en función de la política demográfica china (Bongaarts y Greenhalgh, 1985; Greenhalgh, 2008; Feng, Cai y Gu, 2013; Clarín, 2020; Sadeque, 2020). Según Cancelado Franco (2020: 35) "los nuevos mercados, ${ }^{7}$ marcaron las confrontaciones bélicas de la historia reciente, previa a las guerras mundiales".

Dicho de otro modo, los aspectos paradigmáticos asociados a la gubernamentabilidad se identificaron en los corpus legislativos relacionados a las leyes de estadística que determinaron dos experiencias gubernamentales paralelas en el tiempo (Esquema 2).

El análisis en profundidad del caso argentino se justifica en tanto es uno de los sistemas estadísticos que integran el Mercosur. ${ }^{8}$ La complejidad de dicho sistema se aprecia al examinar el entorno, es decir, varios aspectos de las permanencias y cambios en el sistema político, el ordenamiento jurídico, la organización administrativa, la estructura económica, las condiciones socioculturales y el desarrollo científico y tecnológico ligados a la ley

\footnotetext{
${ }^{7}$ En cuanto al mercado de petróleo, Hitler recibió el apoyo del millonario anglo-holandés Henri Deterding, director del grupo Royal Dutch/Shell, enemigo del "régimen bolchevique ruso" que se apropió de la empresa Shell en Bakú (Azerbaiyán). Franco durante la Guerra Civil Española (1936-1939) recibió petróleo por al menos seis millones de dólares de la compañía estadounidense Texaco.

${ }^{8}$ El proyecto marco se denomina Dato-no dato: sistemas estadísticos nacionales y derechos humanos universales en países del Mercosur. Diagnóstico y aporte metodológicos. Véase Masciadri: 2017, 2018, 2021.
} 
17.622/1968. Para ello se utilizaron dos decretos secretos desclasificados paradigmáticos (InfoLEG) y se recurrió al acervo documental de la Biblioteca Digital UNESCO DOC los que se complementaron con documentos hallados en el Servicio Histórico del Ejército (SHE) y de Cancillería, así como, a publicaciones del Ministerio de Defensa y de la Comisión del Arma de Comunicaciones e Informática. Información adicional se halló en el archivo del SERPAJ. Además de revisar las investigaciones especializadas en doctrinas militares hegemónicas, el problema de la emergencia en el sistema constitucional e historia del periodo 1930-1983 trabajados en estudios previos. Para el examen internacional de la discriminación se consultaron documentos gubernamentales, investigaciones de la Biblioteca Digital UNESCO DOC.

Esquema 2: Representación para la comparación entre entorno y leyes de estadística

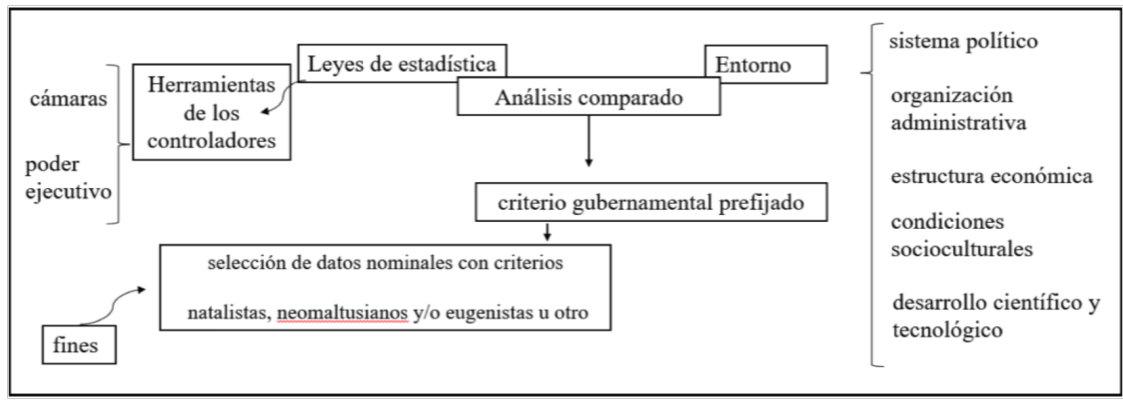

Fuente: elaboración propia.

El estudio exploratorio del entorno de la ley sobre el registro de la población israelí se realizó mediante bases de datos del Knesset o parlamento israelí e información sobre el tratado de libre comercio Israel-Mercosur provienen del Sistema de Información sobre Comercio Exterior de la Organización de los Estados Americanos (SICE).

De fondo, el hilo conceptual que conduce a la reflexión final distingue elementos paradigmáticos de las doctrinas demográficas, de la historia de la empresa IBM y de la historia de las ciencias presentes en las figuraciones sobre el proceso de civilización y tecnificación de Norbert Elias que expresan tensiones, conflictos y cambios que no pueden entenderse sin estudiar varias peculiaridades de la condición humana en interdependencia (Esquema 3). 
Esquema 3: Comparación entre entornos y leyes de estadística: dos experiencias

\section{Experiencia argentina: Sistema Estadístico Nacional (SEN)}

Pasadas las dos guerras mundiales, los rasgos conservadores del Estado argentino se expresaron en la recuperación, a partir de 1930, del poder perdido por la Iglesia católica (Zanatta, 2005) de gran incidencia en la rama castrense, la que adhirió a la Doctrina de Defensa Nacional.

Dicha doctrina comenzó a plasmarse con el golpe del 4 de junio de 1943 y se extendió hasta 1955 con el derrocamiento de Perón. Se manifestó, también, en la posición neutral que adoptó durante casi toda la Segunda Guerra Mundial (19391945), cuando el bloque de los Aliados se enfrentó al Eje nazi fascista. En dicho contexto se creó la Dirección General de Estadística del Ejército para ejecutar actividades estadísticas vinculadas con abastecimiento y movilización, y para ensayar tipos de tarjetas perforadas.

Tiempo después, el $\mathbf{6}$ de septiembre de 1951 durante el gobierno constitucional del general Juan Domingo Perón, el Senado y la Cámara de Diputados reglamentaron la Ley 14.046 de Censos y Estadísticas que materializó la confluencia entre estadísticas civiles y militares.

Dicha norma fue reemplazada durante la vigencia de la Doctrina de Seguridad Nacional, por la Ley 17.622 del 25 de enero de 1968 que rige desde entonces el SEN y que reforzó la característica señalada en tanto ubica, a los Comandos en Jefe de las Fuerzas Armadas (CJFA) entre los órganos centrales de estadística y, especifica que el Instituto Nacional de Estadística y Censos (INDEC) debe organizar un centro para el intercambio de información nacional e internacional.

Dicho articulado - expresión pública de la injerencia militar en materia de población en el SEN- posibilitó visibilizar a la Dirección de Información y Sistematización de Datos (DISCAD), una repartición administrativa pero militar creada, confidencialmente, a comienzos de 1968 durante la dictadura del general Juan Carlos Onganía. Hasta donde se ha logrado investigar durante la dictadura de la autodenominada Revolución Argentina (1966-1973), el tercer peronismo (1973-1976), la última dictadura militar (1976-1983) y durante los primeros años de la transición democrática (1983-1989), la DISCAD (1968-1990) coordinó a personal militar y civil expertos en investigación operativa.

Se conoce que hacia 1969, el Sistema de Computación de Datos (SCD) contaba en el país con 250 computadoras operativas para el ingreso de datos mediante fichas o tarjetas perforadas. En lo que respecta a datos poblacionales, la Secretaría de Hacienda en coordinación con el INDEC operaron el Centro SCD con equipos IBM bajo la dirección del contador público nacional Roberto C. Luzzani (De la Cuesta Ávila, 2002). 
Esquema 3: Continuación

\section{Experiencia israeli: registro de la población}

Tras Segunda Guerra Mundial se fundó el Estado de Israel (14 de mayo de 1948) que heredó el sistema legal del gobierno británico, aunque, las trasformaciones necesarias para la organización del nuevo país las inició el Consejo Estatal Provisional (Mayo 14, 1948-Febrero 14, 1949) mediante ordenanzas, entre otras, The Prevention of Terrorism Ordinance, 5708-1948.

Las reformas prosiguieron con la Asamblea Constitucional, luego denominada primer Knesset (Febrero 14, 1949-Agosto 20, 1951) que como una de sus acciones más destacadas plasmó la Nazis and Nazi Collaborators (Punishment) Law, 5710, No. 64, 1950 que penalizó los crímenes contra el pueblo judío, contra la humanidad y los crímenes de guerra ocurridos en el contexto descripto.

En el mismo sentido, la norma sobre Prevención y Sanción del Crimen de Genocidio, 5710, No. 31, 1950, a la vez que sanciona las conductas genocidas, protege a la población de las políticas segregacionistas esgrimidas por los Estados con la intención de destruir, total o parcialmente, a un grupo nacional, étnico, racial o religioso.

Es importante revisar el caso israelí pues el compromiso de administrar y actualizar el Registro de la Población lo asume el Ministerio del Interior (Administración del Registro de la Población) y, la producción estadística recae sobre la Oficina Central de Estadística, dependiente del Ministerio de Salud y Bienestar que compila las estadísticas habiendo creado en 1956, la Comisión Nacional de Estadísticas Vitales y Sanitarias (Naciones Unidas, 1985: 16).

Asimismo, la Population Registry Law, 5727, No. 65, 1965 instituye en su capítulo primero, la aplicabilidad de la norma a los residentes según: 1) nombre y apellido; 2) nombre de los padres; 3) fecha y lugar de nacimiento; 4) sexo; 5) grupo étnico;

6) religión; 7) estado personal (soltero, casado, divorciado, viudo); 8) nombre del cónyuge; 9) nombre, fecha de nacimiento, sexo de los hijos; 10) nacionalidad/es presente/s y pasada/s; 11) dirección; 12) año de ingreso al país; 13) fecha de inicio de la residencia.

Fuente: elaboración propia. 


\section{ENTORNO Y LEY DE ESTADÍSTICA: EXPERIENCIA ARGENTINA}

Existe coincidencia en afirmar que las dictaduras militares utilizaron datos personales para la planificación de la desaparición forzada de personas (UNESCO, 2007: 61) lo que refuerza la necesidad de reforma de la ley de estadística que no es exhaustiva en relación con el tópico confidencialidad de los datos recabados con fines estadísticos por dos motivos fundamentales: i) la imbricación normativa que incidió en la configuración de los órganos centrales de estadística; ii) varios aspectos del entorno.

En cuanto a las permanencias y cambios del sistema político argentino ha pesado en él, la aplicación del estado de sitio coincidiendo, a su vez, con el máximo despliegue planetario del estado de excepción que devino en una praxis común, luego de la puesta a prueba de los mecanismos y dispositivos del estado de excepción como paradigma de gobierno durante la Primera Guerra Mundial (Agamben, 2007). ${ }^{9}$ Dicha práctica gubernamental redundó en la paulatina erosión de los poderes legislativos del parlamento a nivel global y local que se limita, a menudo, a ratificar disposiciones emanadas del ejecutivo con decretos que tienen fuerza-de-ley, ${ }^{10}$ siendo la dependencia legal del sistema un indicador del perfil de riesgo de un Estado para el genocidio (Auschwitz Institute for the Prevention of Genocide and Mass Atrocities, s./f.).

Y con fuerza-de-ley es como se reglamentó la norma que rige el Sistema Estadístico Nacional (SEN) actualmente. Situación histórico-jurídica asociada, asimismo, con una trama administrativa y burocrática militar previa en la que incidió también la doctrina de facto: según Périès (2009: 391-434) desde el 10 de septiembre de 1930, la Corte Suprema de Justicia convalidó los actos jurídicos realizados por funcionarios bajo poder de facto, alineándose así con las fuerzas armadas hasta 1983; para Negretto (1994: 119), en cambio, dicha alineación ocurrió desde 1947. Por ello no hay que omitir tampoco que el contexto de producción de dicho aparato fue la Doctrina de Seguridad Nacional (DSN) que estableció criterios gubernamentales explícitos e implícitos de segregación en torno a la figura de la subversión interna. ${ }^{11}$

\footnotetext{
${ }_{9}^{9}$ Francia, Alemania, Suiza, Italia, Inglaterra y Estados Unidos tuvieron un papel destacado en la generalización de los dispositivos gubernamentales de excepción. En Alemania, la historia del artículo 48 de la constitución de Weimar se vincula al periodo de entreguerras y permite entender el acceso de Hitler al poder (Agamben, 2007: 33; 44).

${ }^{10} \mathrm{La}$ base de datos realizada por el proyecto Sin Fin existentes en el sitio de Memoria Abierta indica que 156 leyes y 261 tratados sancionados por la última dictadura militar argentina continúan vigentes.

${ }^{11}$ De acuerdo con Daniel Feierstein en el genocidio reorganizador argentino, las condiciones materiales para su producción que nada tienen que ver con la demonización remiten a procesos
} 
En efecto, durante la dictadura del general Edelmiro Farell, con el coronel Juan Perón en el Ministerio de Guerra y el contralmirante Alberto Teisaire en el Ministerio del Interior, el 17 de octubre de 1944 por decreto presidencial se creó, la Dirección General de Estadística del Ejército ${ }^{12}$ para ejecutar todas las actividades estadísticas vinculadas con abastecimiento y movilización, y para ensayar tipos de tarjetas perforadas. Tiempo después, el 6 de septiembre de 1951 durante el gobierno constitucional del general Juan Domingo Perón, el Senado y la Cámara de Diputados reglamentaron la Ley 14.046 de Censos y Estadísticas que materializó, la confluencia entre estadísticas civiles y militares (Masciadri, 2013).

Norma que durante la vigencia de la DSN fue reemplazada por la 17.622 del 25 de enero de 1968 que rige desde entonces el SEN. Esta última legislación reforzó la confluencia aludida posicionando a los Comandos en Jefe de las Fuerzas Armadas (CJFA) entre los órganos centrales de estadística, especificando que corresponde al Instituto Nacional de Estadística y Censos (INDEC) organizar un centro para el intercambio de información nacional e internacional. Dicho articulado — expresión pública de la inje-

previos: construcción de una otredad negativa, hostigamiento, aislamiento, debilitamiento sistemático, realización simbólica, aniquilamiento material. Genocidio que posibilitó su puesta en marcha y su consumación "al convertirse tanto en un ideario como en una praxis criminal" ya que como observa Martín Lozada (2014: 42), el ideario manipuló el término 'subversivo' mediante la adición de elementos simbólicos sucesivos: durante la dictadura de la autodenominada Revolución Libertadora se lo utilizó para descalificar a sindicalistas y disidentes políticos, a finales de 1973 se la empleo para hacer referencia a los sectores que militaban dentro del peronismo y se lo asimiló a terrorista y durante el mandato de María Estela Martínez de Perón se lo adjudicó a todos los sectores movilizados a quienes se demonizó y se los definió como enemigos internos del sistema occidental y cristiano inculpando a los judíos de crímenes abominables y de vicios hereditarios. Véase Bilbao y Lede, 2016.

${ }_{12}$ El contexto de producción de dicha repartición gubernamental fue la Doctrina de Defensa Nacional (DDN). De acuerdo con Bernetti y Puiggrós (1993: 49-51): lo que Perón enunció en La Plata en 1944 como ministro de Guerra, es lo que enseñó en Buenos Aires como profesor de los oficiales del Estado Mayor en 1932 en la Escuela Superior de Guerra: "[P]oner en funcionamiento las energías globales de la Nación frente a la guerra que se avecina; entender este proceso como un combate político, militar, cultural e industrial". Por ello adoptó el modelo del acuerdo de Bismarck y Moltke reclamando en 1932, la creación de un Consejo de Defensa Nacional y el puesto de Comando en Jefe del Ejército en tiempo de paz, dejando al ministro de Guerra las funciones político-administrativas y pasando al Comandante en Jefe las militares que debe "sentir en sí algo de estadista". Dicha perspectiva performativa que imbuyó con su pedagogía estratégica la ciencia y la praxis de la educación social peronista exigiendo la subordinación hasta de pensamiento remite, asimismo, al rol cohesionante de la religión ligado a la tradición hispana y civilizatoria de la "cultura grecorromana, de la que debemos ser y somos parte" en lo que hace a "su fe, su lengua y su sangre". No hay que desconocer que Perón fue agregado militar a la embajada argentina en la Italia fascista (1939-1941) y no ocultaba su admiración por ese régimen además de que estuvo exiliado en la España franquista. Es importante notar que el rol cohesionante de la religión aludido fue un rasgo compartido por todas las dictaduras con Perón. Además de que esas palabras de Perón sobre la cultura grecorromana pueden leerse en clave demográfica (Gonnard, 1969) pues la fecundidad, la nupcialidad y las migraciones diferenciales estuvieron entre sus centros de interés (Llorens y Correa Ávila, 1948; Senkman, 1989; Goñi, 2017). Elementos que explican la consagración del fundamentalista católico Oscar Ivanissevich como ministro de Educación (primer, segundo y tercer gobierno peronista). 
rencia militar en el SEN_ permitió hallar la Dirección de Información y Sistematización de Datos (DISCAD), una repartición del ámbito administrativo pero militar creada, confidencialmente, a comienzos de 1968.

Por otra parte, si se enfoca el periodo 1930-1983, es importante notar que el estado de excepción se aplicó por periodos cada vez más extensos conforme al incremento de la actividad represiva del Estado ante el aumento de los movimientos sociales emergentes. Por ello, si bien heterogéneo desde el punto de vista de la política formal — de facto, de derecho-, el periodo 1969-1983 se homogeneizó debido al estado de sitio y al concepto de seguridad nacional que se traspuso con mayor realismo técnico.

En ese sentido fue sancionada con fuerza-de-ley la llamada 16.970 de Defensa Nacional de 1966 que fundamentó, la interdependencia entre seguridad y desarrollo y que originó los Sistemas Nacionales de Planeamiento y Acción para la Seguridad — que contaba con el Consejo Nacional de Seguridad (CONASE), el Comité Militar y la Central Nacional de Inteligencia (CNI), dependientes del Poder Ejecutivo- y el Sistemas Nacionales de Planeamiento y Acción para el Desarrollo - compuesto por el Consejo Nacional de Desarrollo (CONADE) -.${ }^{13}$ Competía al CONASE requerir los datos, estadísticas y demás informaciones directamente de los ministerios nacionales, comandos en jefe, secretarías de Estado, gobiernos de provincia, intendencias municipales, organismos públicos y entidades privadas dependientes del CONADE.

Ha sido investigada por Guillermo O'Donnell (2009: 56), la especificidad histórica del Estado Burocrático Autoritario (EBA) en relación con otros tipos de estados autoritarios, esto es, que "quienes llevan a cabo y apoyan su implantación [las clases dominantes] coinciden en que el requisito principal para extirpar la crisis es subordinar y controlar estrictamente al sector popular, revertir la tendencia autonomizante de sus organizaciones de clase y eliminar sus expresiones en la arena política". Y las clases dominantes utilizaron todos los medios "para extirpar la crisis que viciaba el binomio seguridad-desarrollo" siendo la ley 17.622 que rige el SEN, un componente de la especificidad histórica del EBA. Es conocida la Clasificación Internacional Uniforme de Ocupaciones y algunas de sus categorías: obrero, estudiante, maestro, abogado y demás; datos personales que, vinculados con el nombre, el apellido y la dirección pueden redundar en la identificación.

${ }^{13}$ La norma establecía el "servicio civil de la defensa nacional" incluyendo a todos los habitantes sin distinción de edad. Véase, Ministerio de Cultura y Educación, 1977. 
En otros términos, datos almacenados por la administración y conservados con el identificador habrían permitido a la DISCAD ${ }^{14}$ consolidar archivos patronímicos de los sujetos y de sus vínculos (parentales, filiales, laborales, patrimoniales y demás). En lo que respecta a datos poblacionales, la Secretaría de Hacienda en coordinación con el INDEC operaron el Centro SCD con equipos IBM bajo la dirección del contador Roberto C. Luzzani. Pero todo EBA es resistido ${ }^{15}$ y al revisar la síntesis biográfica de Carlos Noriega, la presunción se hace evidente pues se inició trabajando en CONADE hacia 1962 y fue detenido-desaparecido en 1977 siendo director del INDEC (1973-1977) aunque en su legajo figura su renuncia.

Es importante notar que el Sistema de Información y Computación de Datos (SICAD) fue "un sistema integrado por personas, máquinas y medios montado para actuar en los campos de aplicación de la fuerza en apoyo de la conducción estratégica operacional, táctica, administrativa y financiera" que mediante la técnica de investigación operativa desarrolló procedimientos y métodos para concretar los objetivos de la conducción militar mediante computadoras de alta velocidad (EMGE, 1968).

En lo referente a la estructura económica y a las condiciones socioculturales del entorno de la ley 17.622 es clave revisar alianzas estratégicas paradigmáticas de la última dictadura militar argentina en el terreno de la informática presentando tres sucesos alusivos relevantes: 1) Decreto S 585 del 9 de marzo de 1978; 2) I Conferencia UNESCO-IBI realizada entre el 28 de agosto el 6 de septiembre de 1978; 3) Decreto S 1827 del 11 de agosto de 1978. Hechos que al mismo tiempo bosquejan otros aspectos de la trama burocrática contigua a los desarrollos SCD en el país vinculados al desarrollo científico y tecnológico.

\footnotetext{
${ }^{14}$ La Dirección General de Estadística creada en 1894 (Naciones Unidas, 1985: 5) fue uno de los precursores de la DISCAD junto a la Dirección General de Administración, el Instituto Geográfico Militar y la Inspección General Territorial.

${ }_{15}$ Entre los empleados del actual Ministerio de Economía detenidos-desaparecidos: Raúl Miranda, Carlos Gustavo Cortiñas - hijo de Nora Cortiñas- y Hugo Bivi de ex CONADE, ex Instituto Nacional de Planificación Económica e INDEC; Aída Fucinos Rielo de la Dirección Nacional de Programación Presupuestaria dependiente de la Secretaría de Hacienda; Graciela Mellibovsky Saidler de Aguas y Energía; Juan Carlos Casariego de Bel de la Dirección General de Asuntos Jurídicos del entonces Ministerio de Economía y Trabajo; Juan Takara Higa de la Dirección General Impositiva (Masciadri, 2013).
} 
Legajos históricos: extracto expediente s01:0357273/2010

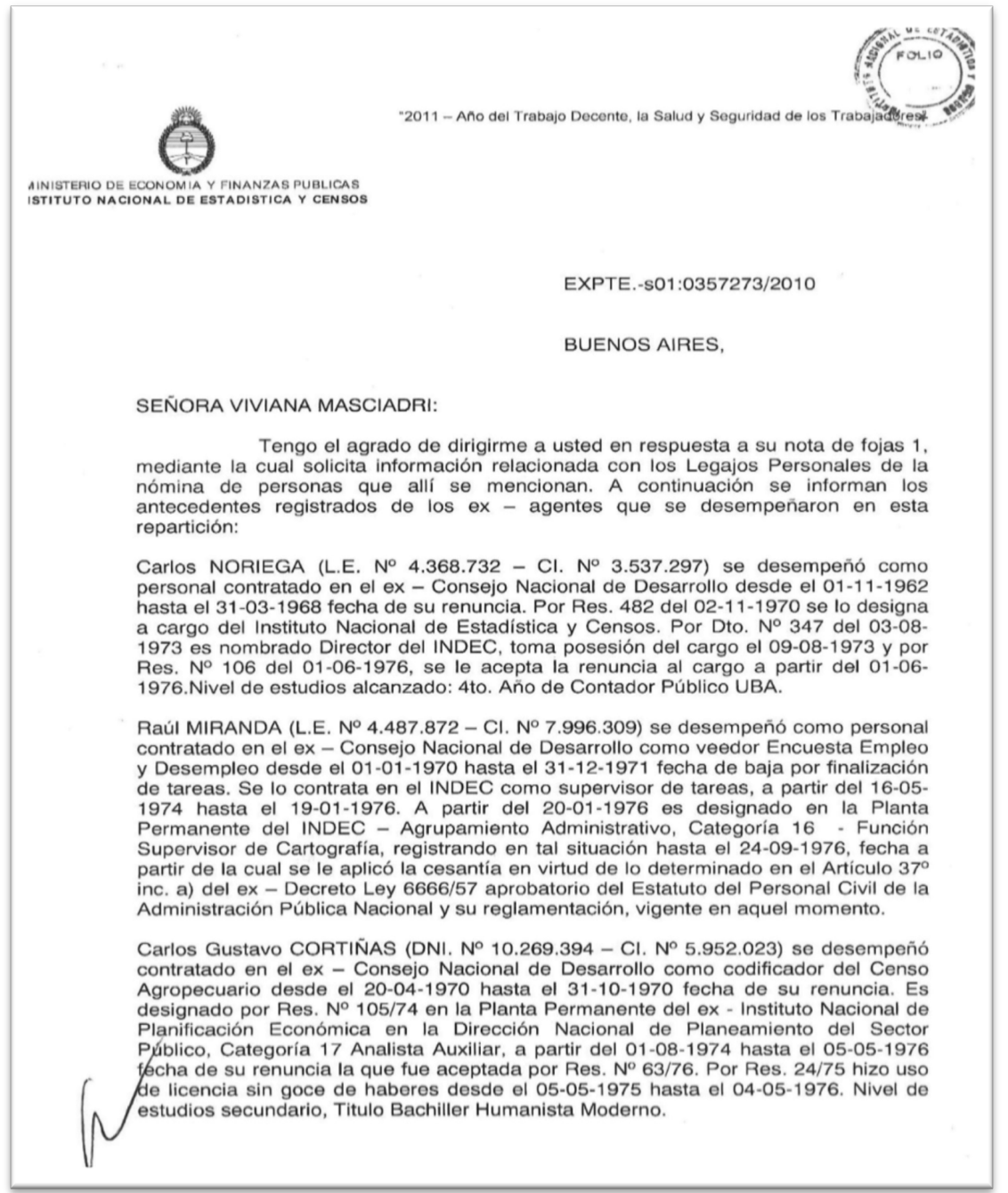

Fuente: Dirección y Gestión de Personal, INDEC, Ministerio de Economía y Finanzas Publicas, 299-2010. 
Mediante el Decreto $S 585$ refrendado por el entonces presidente de facto Jorge Rafael Videla se designó en la Subsecretaría de Informática, al Comodoro (R) D. Oscar Gregorio Vélez secretamente. Aunque Oscar Gregorio Vélez ya había participado como asesor presidencial en SCD durante el onganiato; ${ }^{16}$ momentos incipientes de la informática cuando la secretaria general de la Presidencia organizó las Jornadas SCD/1968 los días 26 y 30 de noviembre en el Banco Municipal de Buenos Aires, organizando, al año siguiente el Congreso SCD/1969 al que concurrieron 1.057 personas. Entre sus participantes se cuenta al ingeniero Horacio Reggini en el panel "Desarrollo de los principios de la sistematización" y las palabras de cierre estuvieron a cargo del secretario de Ciencia y Tecnología, Alberto Carlos Taquini que ocupó ese cargo entre 1968 y 1971.

Cabe destacar que, como resultado de la experiencia adquirida en aplicación de sistemas, en 1970, el IBI (Intergovernmental Bureau for Informatics) eligió a la Argentina para realizar la I Conferencia Latinoamericana de Autoridades Gubernamentales de Informática en la que participaron el Dr. José Dien de Melles Telles (Brasil), el Dr. Efraim Friedman (Chile), el Ing. Luis Fernando Meyer Cabanillas (Paraguay) y el Sr. Dov Cheviev (Israel) (De la Cuesta Ávila, 2002: 44-48).

No hay que soslayar que el proceso de desarrollo vinculado al uso de máquinas expresa demandas económicas, sociales y políticas relacionadas a la gubernamentabilidad sobre todo cuando objetivos de seguridad, de defensa o de poderío económico aparecen ligados a las conquistas de la ciencia y la tecnología. Se ha visto que la seguridad era la herramienta defensiva "que obraba a la manera de un escudo protector del desarrollo" (Comando en Jefe del Ejército, 1967) lo que explica la extensa zona del poder ejecutivo que comprendió a los ministerios, secretarías, organismos y dependencias vinculadas al Ministerio de Cultura y Educación, del cual se desprende la Comisión Nacional Argentina para UNESCO y la Secretaría de Ciencia y Tecnología de la cual depende el CONICET (Esquema 4).

\footnotetext{
${ }^{16}$ La aprobación de los desarrollos SCD la realizó el dictador ultracatólico Juan Carlos Onganía que, junto al secretario general de la oficina de Presidencia, el coronel oficial ingeniero militar Carlos Vidueiro, designó al comodoro retirado Oscar Gregorio Vélez y al teniente coronel retirado José Javier de la Cuesta Ávila como asesores en sistematización de datos. Se conoce que hacia 1969, el Sistema de Computación de Datos (SCD) contaba en el país con 250 computadoras para el ingreso de datos mediante fichas perforadas involucrando a instituciones que poseían máquinas para los Centros: Centro Único de Procesamiento de Datos (CUPED), SCD/Yacimientos Petrolíferos Fiscales, SCD/Banco Nación, de Cálculo de la Universidad Tecnológica Nacional, $\mathrm{SCD} /$ Dirección General Impositiva, INDEC, de Computación Universidad de Buenos Aires. Hasta donde se pudo investigar durante la dictadura de la autodenominada Revolución Argentina (1966-1973), el tercer peronismo (1973-1976), la última dictadura militar (1976-1983) y la transición democrática (1983-1989), la DISCAD (1968-1990) coordinó a expertos militares y civiles en investigación operativa.
} 


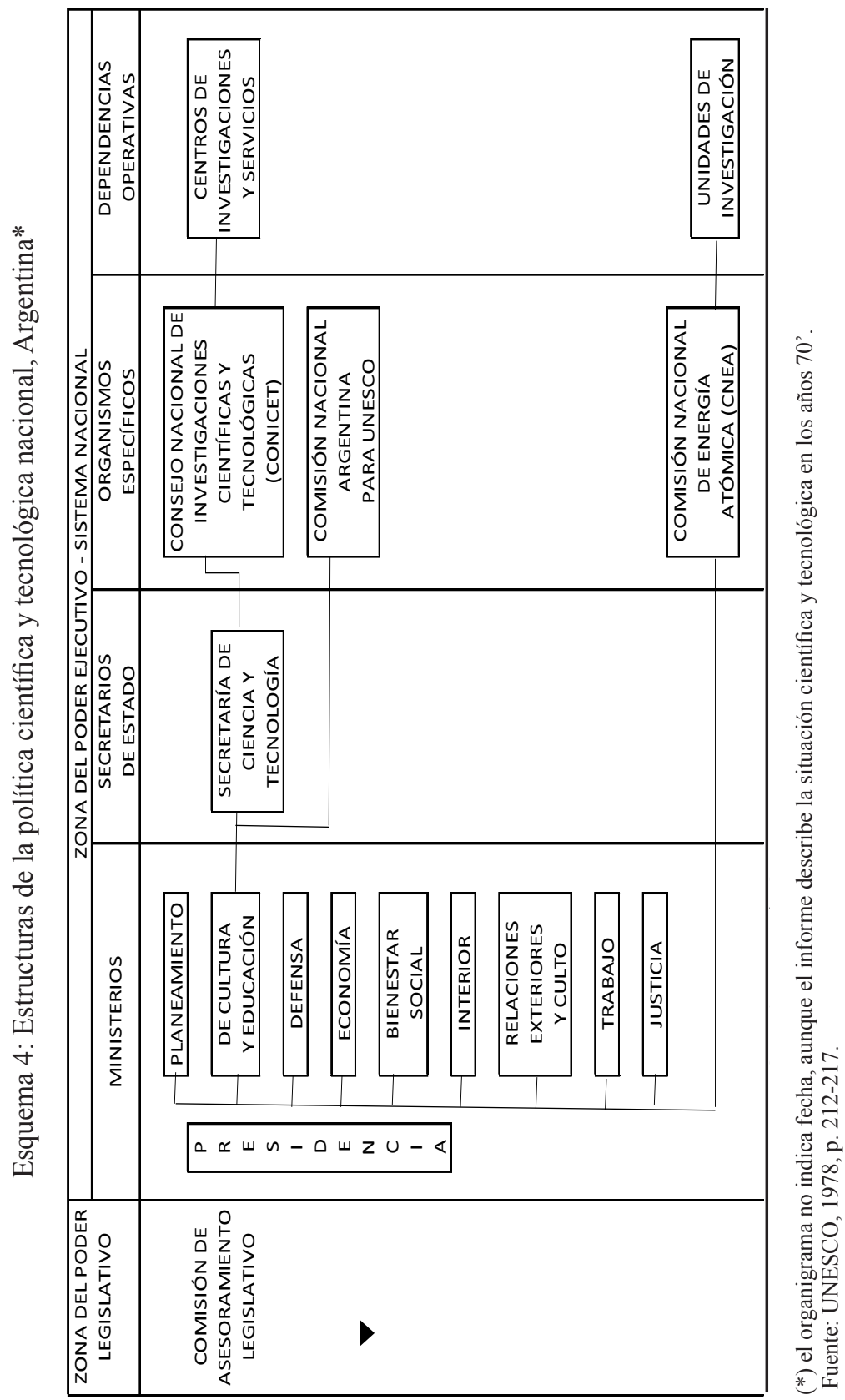


Es importante reflexionar sobre el hecho que en las distintas áreas del CONICET católicos de derecha ocuparon funciones públicas relevantes durante aquel periodo predominando católicos integristas y del nacionalismo de derecha (Mignone, 2013: 201; O’Donnell, 2009: 445).

En cuanto a la UNESCO, si bien Argentina se afilio el 15 de septiembre de 1948 fue durante la XIV Conferencia General realizada en París el 25 de octubre de 1966 que se designó presidente de esta al Sr. Attilio dell'Oro, prestigioso abogado que había sido ministro de Educación ${ }^{17}$ durante el gobierno de facto de la autodenominada Revolución ${ }^{18}$ Libertadora. Años después durante la XVI Conferencia General (París, 12 de octubre al 14 de noviembre de 1970) de la que participaron 124 Estados miembros, 2 asociados, 2 representantes de Estados no miembros, 7 de las Naciones Unidas y sus organismos especializados, 16 de organizaciones intergubernamentales y 114 de organizaciones internacionales no gubernamentales, el Sr. Attilio dell'Oro Maini (Argentina) obró como presidente y un único delegado de República Federal de Alemania, Canadá, Ecuador, Estados Unidos de América, Francia, India, Jamaica, Japón, Madagascar, Nigeria, Reino Unido, Tanzania, Unión de Repúblicas Socialistas Soviéticas, Venezuela y Yugoeslavia obraron como vicepresidentes.

Mientras tanto, en Argentina, la dictadura de turno comandada por Roberto Marcelo Levingston extendía su zona de poder ejecutivo durante estado de sitio (Valderrama, 1995: 174; 200).

A fin de examinar la trascendencia gubernamental de la elección de Argentina para la realización de la I Conferencia Latinoamericana de Autoridades Gubernamentales de Informática (1970) es significativo destacar que el IBI tuvo sus orígenes en el International Computation Centre (ICC) creado por la UNESCO en 1951 y que inició sus actividades en 1961 como un centro de cálculo destinado a la comunidad científica internacional que en aquella época no disponía de máquinas de cálculo debido a su elevado

17 En 1968, la UNESCO reaccionó en contra de las manifestaciones juveniles universitarias que acontecieron en varias regiones del mundo por considerarla una "crisis de la juventud" vinculada a una "crisis moral de la sociedad", y la educación ocupaba "naturalmente" el centro siendo la nueva orientación no "para" sino "con" la juventud. Años después en la XVIII Conferencia General que se celebró en Paris (17 de octubre al 23 de noviembre de 1974), el 14 de noviembre, en sesión plenaria, se rindió homenaje al director general saliente, Sr. René Maheu: intervinieron el presidente del Consejo Ejecutivo y el representante de la Santa Sede, Monseñor Benelli quien anunció que el Papa condecoró con el Premio de la Paz «Juan XXIII» a la UNESCO (Valderrama, 1995: 181-182; 228).

18 La interrupción del orden constitucional con un ataque aéreo contra la Plaza de Mayo simbolizó la anómica enemistad entre peronistas y antiperonistas. Sin embargo, de acuerdo con Arendt (2008: 44-45), una revolución es más que una insurrección triunfante y no se puede identificar a ésta con cualquier golpe de Estado pues éstos y las revoluciones palaciegas deben comprenderse como fenómenos "mediante los cuales el poder cambia de manos de modo diverso" y donde "el cambio que supone está circunscrito a la esfera de gobierno". 
costo. Aunque el ICC se vio superado por la velocidad de los cambios tecnológicos al punto que hacia 1969 estuvo al borde de su extinción. Fue cuando el argentino Fermín Bernasconi comenzó con la transición del ICC al IBI desde Roma.

En tanto organización intergubernamental, el IBI congregó un máximo de 43 países miembros hasta 1985, año en que comenzó su decadencia cuando Francia retiró su membrecía, le siguió España en 1986 e Italia en 1987 lo que condujo a la disolución de esta organización en 1989. El IBI organizó varias conferencias del tipo hasta arribar, a la I Conferencia UNESCO-IBI realizada en Torremolinos Málaga (España), entre el 28 de agosto y el 6 de septiembre de 1978 (UNESCO, IBI, 1979). ${ }^{19}$

Para profundizar sobre estos hechos alusivos a la historia de la informática hay que conocer que durante la I Conferencia UNESCO-IBI de 1978, el ministro de la presidencia del Gobierno de España Sr. José Manuel Otero Novas actuó como presidente del evento ${ }^{20}$ y el subsecretario de informática de Argentina Sr. Oscar Gregorio Vélez intervino como vicepresidente siendo relator de la reunión, el director de Investigación Científica y Tecnológica de Argelia, Sr. Mentalechta. ${ }^{21}$ También participaron en calidad de vicepresidentes los delegados por: i) China el jefe de la Oficina de Ciencias Básicas de la Comisión Nacional de Ciencia y Tecnología, Sr. Yen; ii) Francia el director de Industrias Electrónicas e Informática ministro de Industria, Sr. Pelissolo; iii) Irán el viceministro para la organización del Plan y Presupuesto de Informática, Sr. Firuz Vakil; iv) Iraq el director general de NCC, Dr. Albayati; v) Italia el delegado permanente ante la UNESCO,

19 En la preparación de la I Conferencia UNESCO-IBI propiamente tal colaboraron desde el IBI, el Comité de Estrategia y Políticas sobre Informática SPINCO con expertos de países desarrollados y no desarrollados, y el MINEXSPIN integrado por expertos que asesoraban al director de la UNESCO Amadou-Mahtar M'Bow pues ambas instituciones desplegaron estrategias gubernamentales para el intercambio internacional de políticas informáticas en el periodo 1969-1989. El 24 de noviembre de 1970 el Sr. Amadou Mahtar M'Bow (Senegal) por cese del Sr. C. Flexa Ribeiro (Brasil) fue designado subdirector general del Sector educación. El 15 de noviembre de 1974 , en sesión plenaria, fue elegido director general, por un periodo de seis años siendo el sexto director general de la UNESCO. El 27 de septiembre de 1980, M'Bow fue reelecto por siete años. Los presupuestos durante su dirección fueron: bienio 1975-1976, 169'992,000 dólares; bienio 1977-1978, 224’413,000 dólares; bienio 1979-1980, 303’000,000 dólares; trienio 19811983, 625’374,000 dólares (Valderrama, 1995).

${ }^{20}$ En el párrafo 62 se menciona que luego del "acto de apertura, y a propuesta del jefe de la delegación de la Argentina, secundado por los jefes de las delegaciones del Líbano, Arabia Saudita e Italia, la Conferencia eligió por aclamación, como presidente, al jefe de la delegación de España" (UNESCO, IBI, 1979: 14).

${ }_{21}$ El documento de trabajo Estrategias y políticas en materia de informática fue la base de dicha Conferencia y en él se menciona que, los tipos y niveles de órganos y entidades responsables de la informática a finales de los años 70 eran diversos y en algunos casos como los de Argentina y de Irán comprendieron a las subsecretarías de Estado y a las comisarías generales como en Argelia. En dichos países un órgano único centralizaba el control y el desarrollo de la informática del país: en Argelia ese órgano fue el Commissariat National à l'Informatique (UNESCO, 1978 b). 
Sr. Carducci Artenisio; vi) Nigeria el director adjunto de informática, Sr. Awomolo; vii) Estados Unidos de América el profesor visitante Duke University J.E. Fobes; ${ }^{22}$ viii) URSS el viceministro de Automoción de Instrumentos y de Medios de Automoción y de Telecomunicaciones, Sr. Genni Kavalerov y ix) Yugoslavia ${ }^{23}$ el presidente del Consejo de Informática Dr. Iván Mecanovic. Por los estados que actualmente constituyen el Mercosur asistieron las delegaciones de: Brasil encabezada por Geraldo Holanda Cavalcanti representante de su país ante la UNESCO; de Bolivia presidida por el gerente general M. Basilio Plaza Martínez; de Venezuela encabezada por el director general de Planificación y Presupuesto del Ministerio de Medio Ambiente Luis José Diaz Zuloaga; de Paraguay representada por el consultor Néstor Manuel Brítez Airaldi; de Uruguay dirigida por el ministro consejero de la Embajada del país en España, Adolfo Castells Mendivil. Por Israel asistió Dov Chevion, director del Office Mechanization Centre Israel.

Resulta evidente que la participación del comodoro (R) D. Oscar Gregorio Vélez reforzó la credibilidad intergubernamental de la dictadura argentina ante el mundo, ${ }^{24}$ por tanto, la mesa de cierre confirió a la delegación argentina las palabras de clausura en la persona de Luis M. Laurelli, ${ }^{25}$ aun cuando también participó Luis Pedro Beccaria, director de Políticas y Normas de la Subsecretaría de Informática. En efecto, mientras que el nombramiento de Oscar Gregorio Vélez en la Subsecretaría de Informática se realizó mediante un decreto secreto, durante la I Conferencia UNES$C O-I B I$ se sostuvo que:

[Y]a no es un secreto (...) que la informática es un instrumento insustituible para el conocimiento de la profusa información que, a diario, nos llega y que permite poner a nuestra disposición aquellos datos que están en la base de toda

${ }^{22}$ El 1 de marzo de 1964, el Sr. John E. Fobes (Estados Unidos de América) fue nombrado subdirector general para la administración de la UNESCO. El 31 de diciembre de 1977 cesó, por jubilación, como director general adjunto (UNESCO) siendo reemplazado, el 6 de junio de 1978 por el Sr. Federico Mayor Zaragoza (España), que había sido catedrático de bioquímica, rector de la Universidad de Granada y subsecretario del Ministerio de Educación (Valderrama, 1995: 247). ${ }_{23}$ Feierstein (2016: 374-375) analiza el conflicto político que envolvería años después a la República Federativa Socialista de Yugoslavia y que determinó su desmembramiento y su reconfiguración en Bosnia-Herzegovina, Croacia, Eslovenia, Macedonia, Montenegro y Serbia.

${ }^{24}$ En el informe final consta el discurso del Rey Juan Carlos I de España que menciona que: "como todo logro científico (...) no tiene posibilidades de desarrollarse si no se comparte con los demás. Las telecomunicaciones son y deben ser, en este sentido, el vehículo de la informática" (UNESCO, IBI, 1979: 64). Es así como en, el año 1994, el oficial de Comunicaciones del Ejército y la DISCAD se fusionaron en la Dirección de Sistemas de Comunicaciones e Informática (DGCI). La actual DGCI es un departamento del Ejército Argentino (Arcángel San Gabriel Comisión del Arma de Comunicaciones e Informática, 2014).

${ }_{25}$ Según el Archivo Histórico de Cancillería, Luis M. Laurelli se desempeñó como jefe de la División de Asuntos Sociales Especiales de la Subsecretaría de Relaciones Exteriores (Ministerio de Relaciones y Culto, 20/8/1981). 
la evolución económica y social de nuestras comunidades" (UNESCO, IBI, 1979: 14; 29-30).

Se menciona, asimismo, que las aplicaciones de la informática constituyen un campo que plantea la transición a una informática de masas para su uso en oficinas, concepción de planos o gráficos asistida por computadoras, correo electrónico, transferencia electrónica de fondos para automatizar las operaciones financieras, enseñanza asistida por computadoras, informática doméstica desconectada o conectada, robótica. Por otra parte, en el discurso final del director general del $I B I$, Fermín A. Bernasconi figuran a su entender las acciones a desarrollar a futuro: i) nuevas tecnologías especialmente las miniaturizadas; ii) la normalización y iii) el flujo a través de fronteras; señalando que dichas acciones deben contar con el marco en el que serán ejecutas y los fines a los que están destinadas.

Pero el marco que Fermín Bernasconi trazó aludía a una crisis mundial sin precedentes, a raíz de la extinción de las fuentes energéticas, la explosión demográfica, la desigual distribución del poder y de la riqueza que conducirían a la humanidad a condiciones límites, más allá de los cuales se produciría una desestabilización en cadena con efectos imprevisibles. Todo ello lo vincula a que la informática modifica "la importancia en las principales variables en juego" y las "modificaciones pueden, a su vez, acelerar y agravar dicha crisis" (UNESCO, IBI, 1979: 70).

Ocurre que, tras la Segunda Guerra Mundial, los paradigmas de la explosión demográfica ligada a la composición y calidad de la población, la extensión del movimiento revolucionario en el Tercer Mundo y el holocausto nuclear tiñeron de alarmismo las declaraciones de militares, religiosos, funcionarios y científicos de varias áreas incluida la informática como se ve reflejado en el discurso de Bernasconi. No obstante, el informe general que sintetiza la participación de 267 delegados y de 23 representantes y observadores denominado "La situación actual y perspectivas futuras del empleo de la informática: experiencias en la elaboración de políticas y estrategias nacionales en materia de informática" es más alentador. Aludiendo a los factores de deshumanización en las relaciones sociales se expresa, asimismo, el riesgo de la concentración de la tecnología y del potencial de investigaciones en un número limitado de países y de empresas multinacionales que acentúan las tendencias monopólicas. A ello se contrapone la cooperación y los intercambios regionales e internacionales, en especial, en teleinformática, bancos de datos, mantenimiento, normalización y aplicaciones al tiempo que se menciona que la cooperación debe ser objetiva, sin discriminación, aunque se enuncian los "lazos de sangre", 
"de familia" que determinaron el vínculo entre el IBI y la UNESCO desde 1970 (UNESCO, IBI, 1979: 24, párrafo 48).

En efecto, en aquella época de experimentación en los desarrollos informáticos se proyectaron espacios y prácticas específicos en los ámbitos gubernamentales sobre la base de prejuicios ideológicos (guerrilleros tecnológicos) y étnicos (indios, tribus) que en la trama del poder contribuyeron con la falta de autonomía económica en el campo de la informática de países como Brasil (proyecto COBRA) y Argentina (Adler, 1988: 5990; Jacovkis, 2014; Diaz de Guijarro, et.al., 2015; De Souza Neves, et.al., 2015; Rodríguez Leal y Carnota, Raúl, 2015; Monteiro Fernández, 2015).

Otro factor que alude a la discriminación se encuentra en el Informe de la Comisión I Requisitos básicos previos para el empleo eficaz de la Informática pues allí se menciona, por una parte, el papel de la cooperación internacional llevado adelante entre países africanos, árabes, latinoamericanos y de Europa oriental, aludiéndose, por otra parte, a que un delegado se refirió a la "arabización" 26 en la utilización de la informática vinculada a la electrónica, a las telecomunicaciones y a los sistemas automatizados así como, a las relaciones con la industria y las investigaciones (UNESCO, IBI, 1979: 25-28). En cuanto al Informe de la Comisión II Aplicaciones de la informática, se plantea la desarmonización de las legislaciones sobre los flujos transnacionales de datos que suscitan diversas y complejas problemáticas vinculando entre sí aspectos jurídicos, sociales, económicos y políticos en relación con los datos sensibles que se transmiten por intermedio de transportadores sencillos siendo, un tema de interés no sólo para los Estados y las empresas sino también para los usuarios (UNESCO, IBI, 1979: 29-32).

${ }^{26}$ En la historia del mundo árabe contemporáneo la creación del estado de Israel es considerado un desastre (la nakba) al que suman el triunfo israelí sobre Jerusalén (1967) (Gómez, 2019: 281). Pero los datos publicados por el Religion and State Proyect (RAS) de 2015 indican que, la población mundial rondó las 7’335,774,068 personas de los cuales 2’192,754,068 (29.9 por ciento) son cristianas, 1'671,280,943 (22.8 por ciento) son musulmanas y 14 '671,548 (0.2 por ciento) son judías, aunque la mayoría mundial corresponde a la rama sunní musulmana que representa 19 por ciento, mientras que los católicos representan 15 por ciento y los hindúes 14.5 por ciento. El proyecto RAS localizado en la Universidad Bar Ilan en Ramat Gan coordinado por Jonathan Fox cuenta con el apoyo de la Fundación de Ciencia de Israel, la Cátedra Sara y Simha Lainer en Democracia y Ciudadanía, la fundación John Templeton vinculada a la Asociación de Archivos de Datos de Religión y la fundación Alemania-Israel. Pese a que la población judía constituye una minoría en febrero de 2020, la ONU publicó un listado de empresas que conducen negocios con israelíes que habitan en el barrio judío de Jerusalén y en otras áreas cruzando la Línea Verde de 1949. Para Hillel Neuer, director de UN Watch, es llamativo que, de más de 100 disputas territoriales en el mundo, la ONU eligió poner en una lista negra sólo a dichas compañías. El listado fue solicitado en marzo de 2016 por Kuwait desde el Grupo Árabe de 22 miembros, por Pakistán en nombre del Grupo Islámico de 56 miembros, junto con Sudán, Venezuela, Argelia, Bahrein, Bolivia, Chad, Cuba, Djibuti, Ecuador, Egipto y Libia mediante una resolución del Consejo de Derechos Humanos. Así y todo, durante 2020, Israel firmó acuerdos históricos de paz con los Emiratos Árabes Unidos, Bahrein y otros países de Oriente Medio. 
En cuanto al paradigma del holocausto nuclear mencionado por Bernasconi, no hay que ignorar que la Argentina participó en la Conferencia Preparatoria para la Fundación del Organismo Internacional UNESCO realizada en el Instituto de Ingenieros Civiles (Londres, del 1 al 16 de noviembre de 1945) ${ }^{27}$ Durante aquella Conferencia presidida por la ministra de educación del Reino Unido Miss Ellen Wilkinson se pretendía crear una Organización para la Educación y la Cultura, al tiempo que algunos científicos — como Joseph Needham, Jefe de la Misión Científica Británica a China y el físico Julián Huxley quien luego sería el primer director general de la UNESCO - bregaron para que se incluyera a la Ciencia en el proyecto justificando su postura, a propósito del bombardeo atómico de las ciudades japonesas de Hiroshima y Nagasaki —agosto de 1945- lo que en aquel momento soterró otras discusiones vinculadas al uso de datos personales para la planificación del genocidio perpetrado al pueblo judío por los nazis y sus aliados (Seltzer, 1998; Black, 2001; Seltzer y Anderson, 2001). Es decir, al paradigma del holocausto nuclear no se contrapuso el paradigma de la planificación del genocidio realizado sobre la base de la segregación sistemática de personas que, supuestamente, menoscaban a la especie humana. Aunque a partir de 1947 se inició el proyecto sobre los "Estados de tirantez que afectan a la comprensión internacional" 28 desde las ciencias sociales en el ámbito de la UNESCO (Valderrama, 1995: 39).

Un rasgo característico de la "especie" (Vetta y Courgeau, 2003) se advierte cuando se analiza la observación realizada por Norbert Elias acerca de las prácticas del tradicional método japonés de regulación propia durante la Segunda Guerra Mundial que se resume en el hecho que cualesquiera que fueran las circunstancias, los guerreros japoneses no estaban preparados para la derrota pues su código establece a la captura como una humillación imperdonable que se vio reflejada, asimismo, en la capacidad de expresar placeres sádicos con los prisioneros, ligado a un fanatismo extremo y a su incapacidad de deponer las armas aun en la derrota lo que se modificó luego de la primera bomba atómica americana cuando el empe-

${ }^{27}$ Participaron delegados y consejeros de Arabia Saudi, Argentina, Australia, Bélgica, Bolivia, Brasil, Canadá, Colombia, Cuba, Checoeslovaquia, Chile, China, Dinamarca, Ecuador, Egipto, El Salvador, Estados Unidos de América, Filipinas, Francia, Grecia, Guatemala, Haití, Holanda, India, Irak, Irán, Líbano, Liberia, Luxemburgo, México, Nicaragua, Noruega, Nueva Zelanda, Panamá, Perú, Polonia, Siria, Turquía, Unión Sudafricana, Uruguay, Venezuela (representada por un observador) y Yugoeslavia: 42 países en total.

${ }_{28}$ Se desconoce si dicho proyecto se ocupa del hecho de que 70 mil ciudadanos de origen japonés residentes en la costa occidental luego del ataque de Pearl Harbor, el 19 de marzo de 1942 fueron desplazados (Agamben, 2007: 57-58; Freedom of Information Act, 1974). 
rador japonés estuvo en condiciones de poner freno a dicho código. Como ha escrito Norbert Elias, ${ }^{29}$

[E]n medio de las peculiaridades de tales cambios civilizatorios en la estructura de la personalidad y especialmente en los estándares sociales de autorregulación, prosiguen otros cambios, tal vez económicos y tecnológicos, que se manifiestan sólo después (1998: 486-487).

En efecto, de acuerdo con Fernando Valderrama (1995: 182; 219; 232) desde que terminó la Segunda Guerra Mundial hasta 1968 sucedieron cien guerras y conflictos armados. Sin embargo, la UNESCO durante la XVIII Conferencia (París, 17 de octubre de 1974) sólo sancionó a Israel tras la Guerra de los Seis Días de junio de 1967 y lo hizo tiempo después, cuando concedió estatuto de observador a la Organización para la liberación de Palestina (OLP) mientras que no aprobó la solicitud de ingreso de Israel en la región de Europa, ${ }^{30}$ a lo que se sucedió la suspensión del pago de la contribución de Estados Unidos de América situación que se modificó hacia 1977. Tales disputas sobrevinieron en medio de la crisis del petróleo cuando el gobierno de Estados Unidos de América anunció la devaluación del dólar en diez por ciento (12 de febrero de 1973).

En lo relativo a la estructura económica y retomando la situación particular argentina que se dio en medio de tal situación internacional, en paralelo, el 11 de agosto de 1978, el Poder Ejecutivo Nacional ${ }^{31}$ autorizó, confidencialmente mediante el Decreto $S 1827$, a contratar en forma directa por la suma de 4.762.434 millones de dólares, la adquisición de una "Sistema de Computación" a la compañía para el Comercio Mundial en América y el Lejano Oriente IBM. Dicha transacción se realizó el 11 de mayo de 1978 en la ciudad de Mount Pleasant en Nueva York participando por IBM,

\footnotetext{
${ }^{29} \mathrm{Al}$ conocer algunos datos biográficos sobre nuestro autor se logra contextualizar el mensaje de su vasta obra que permite comprender otro de los aspectos propios de la perpetración de genocidios (Korte, 1998).

${ }_{30}$ El cambiante equilibrio de poder entre Estados se actualizó en la Guerra de Yom Kipur (octubre de 1973) librada contra Israel por Egipto y Siria cuando en el contexto de la Guerra Fría, la coalición árabe lanzó un ataque conjunto que a su término acarreo, el incremento del activismo armado palestino y una confrontación diplomática contra Israel por la mayoría automática que formaron en la ONU, los países árabes y el bloque del Este. Con todo, Egipto reconocería la existencia del Estado de Israel acercándose así al mundo occidental; Siria, en cambio, continuó su alianza con Rusia. Desde la "historia de los conceptos" el término Occidente (Westen) se emplea en contextos de experiencia y articula redes semánticas con diversos significados sociopolíticos, con lo cual, el término adquiere un carácter inevitablemente plurívoco. El término Occidente (Westen) erige su carácter política, cultural y religiosamente; el Este (Osten) y el Oeste (Westen) funcionan - observados en la historia de los conceptos - como grandes estereotipos que frecuentemente dependen de descripciones históricas persuasivas de sí mismo o del extranjero (Ritter, Gründer y Gottfried, 1998; Koselleck, 2001).

31 Tanto Jorge Rafael Videla como el primer director de la DISCAD, Santiago Omar Riveros fueron condenados por cometer crímenes de lesa humanidad.
} 
John L. Collins y por el Comando en Jefe de la Armada Argentina, Juan José Lombardo y Juan Manuel Sosa Escalada, con la traducción de Graciela Alsina. Aludiendo a la metáfora periodística sobre el "síndrome de Eichmann" 32 (El tempo (a), 198-), documentos del acervo documental del SERPAJ refieren que la empresa que suministró los equipos y el soporte técnico para confeccionar listados con propósitos políticos represivos en Argentina y en otras dictaduras de la región fue IBM. De acuerdo con una publicación del Ministerio de Defensa varias personas de los listados comenzaron a ser "tratadas" en 1967 y el "tratamiento" se extendió hasta 1983 inclusive. Ya se revisó lo actuado por la DISCAD en el INDEC y para el intercambio regional de datos, el procedimiento habría comprendido al Condortel (IPPDH, 2015). A lo que se suma los rasgos antisemitas de este genocidio donde, la alianza tecnológica y filosófica entre el régimen nazi y la IBM se reprodujo, en la alianza entre la última dictadura militar y dicha corporación ya que, sobre la base de cálculos modestos, la población judía tuvo en el proceso genocida argentino una sobrerepresentación de más de cinco veces su proporción en la población general (Centro de Estudios Sociales, 2007). ${ }^{33}$ Es importante relacionar el rol que cumplió el CUPED en el manejo de al menos, los registros de los empleados públicos pues dicho centro SCD operó en el ministerio de Bienestar Social desde 1968 y también mientras quedó a cargo del fascista y anticomunista, López Rega, jefe de la triple A.

Siendo que al menos diecisiete sentencias calificaron al caso argentino como un genocidio se instala el alerta, una vez más, sobre el riesgo que representa el monopolio comercial sobre los datos de empresas como IBM,

${ }^{32}$ Adolf Eichmann fue capturado en Argentina en 1960 y trabajó en Mercedes Benz; fundada en Alemania en 1880 se instaló en Argentina en 1951 y en los 70 se encontraba entre las 20 de mayor facturación del país teniendo al Ejército Argentino como su principal cliente. Cierto, en 1951, Mercedes-Benz Argentina se constituyó como filial de la multinacional Daimler Benz AG, la primera automotriz alemana instalada en el país lo que sucedió durante el primer gobierno peronista. Derrocado Perón, en 1955, la empresa fue investigada por conexiones con el nazismo local. Años después, la situación empeoró hasta llegar a la desaparición forzada de entre 17 y 20 obreros de los cuales entre 14 o 15 continúan detenidos-desaparecidos que se suman, a las investigaciones sobre complicidad entre las empresas y la dictadura en casos como el de Ford donde funcionó un Centro Clandestino de Detención, otra de las prácticas sociales genocidas implementadas (Memoria Abierta, 2009; Feierstein, 2014, Dirección Nacional del Sistema Argentino de Información Jurídica, 2015; Goñi, 2017).

${ }_{33}$ De acuerdo con Feierstein (2014: 318-323), las prácticas de hostigamiento como etapa de transición del campo de lo simbólico en tanto construcción de negatividad, al campo de lo material en tanto modalidad de hostigamiento físico paraestatal se vinculó en el genocidio reorganizador argentino con el accionar de la triple A (Alianza Anticomunista Argentina) y en la experiencia del nazismo alemán durante los años treinta con el accionar de las SA. La vulnerabilidad se reconfirmó en dos atentados: el primero realizado el 17 marzo de 1992 contra la embajada y el consulado de Israel en Argentina con un saldo de 22 muertes y 242 heridos y el segundo realizado el 18 de julio de 1994 contra la Asociación Mutual Israelita Argentina (AMIA) con 85 personas asesinadas y 300 heridos. La causa AMIA no se ha resuelto aún. 
que no sólo se especializó en el procesamiento de la información censal desde 1890 (Black, 2001) sino que, al igual que otras empresas abarcó áreas de procesamiento de datos sobre aeronáutica, energía atómica, ingeniería civil, defensa nacional, consumidores, empresas, industria automotriz y petroquímica, seguridad social, transportes, comunicaciones, salud, universidades.

A través de la obra de Adler (1987: 223-237) se conoce que IBM se encuentra radicada en Argentina desde 1923 y que a finales de 1969 poseía 65,9 por ciento del mercado y en 1973 era la trigésima segunda empresa que trabajaba a plena capacidad debido a que los niveles de desarrollo y aplicación de la informática en el país se ubicaron en el nivel básico y operativo en el periodo 1960 y $1980 .{ }^{34}$ Ello explica que, de la producción nacional realizada en IBM, todo menos cinco por ciento de la producción se destinara a la exportación, la mitad de la cual iba a los Estados Unidos, Canadá, el Reino Unido, el Japón y Suecia. A mediados de los setenta, 90 por ciento de los negocios de la industria de la informática (la tercera entre las grandes industrias del mundo) recaía en algunas compañías multinacionales, y sólo una concentraba 67 por ciento del mercado mundial. ${ }^{35}$

Finalmente, el recorte de la gubernamentabilidad realizado en este apartado repone un fragmento de la aporía que representa el no-dato. Y como parte de tal evidencia, aquellas situaciones donde se utilizan datos de registro para la desaparición forzada de personas deben impulsar cambios

${ }^{34}$ En aquel momento los países exhibían cuatro niveles de desarrollo y aplicación de la informática según la clasificación de Naciones Unidas: inicial, básico, operativo y superior (UNESCO b, 1978: 31). El nivel básico refiere a que los centros de decisión públicos y privados conocen y emplean computadoras, pero los materiales, equipos y programas son importados. El nivel operativo alude a que las instituciones del país enseñan informática y algunas son universitarias, las computadoras se utilizan en aplicaciones empresariales, médicas, científicas, tecnológicas o administrativas con algún grado de fabricación de materiales y equipos peri-informáticos, y los sectores público y privado tienden a independizarse de los agentes de ventas de los fabricantes pues existen especialistas.

35 En 1974, el volumen de negocios realizado por los 21 principales fabricantes de computadoras rondó los 36 mil millones de dólares —Estados Unidos de América: IBM, HIS, NCR, Burroughs, Univac, CDC, DEC, Hewlett-Packard; Europa: Honeywell-Bull, CII, ICL, Nixdorf, IBM-F, IBM-D, IBM-UK, IBM-NL, IBM-I; Japón: NEC, Fujitsu, OKI, Nippon-Univac (UNESCO b, 1978: 33) - . En cuanto a la capacidad instalada de máquinas en el mundo, por su valor, $78 \%$ eran de origen norteamericano, los productos de fabricación japonesa equivalían a 4.7 y a 5.8 por ciento los de las empresas de Europa oriental. En cuanto a la proporción de máquinas, 56 por ciento correspondía a la empresa IBM, seguida de Honeybell con ocho por ciento y Univac con 6.5 por ciento. Asimismo, el volumen de negocios de dichas multinacionales era fuera de los Estados Unidos (40-41 por ciento) casi tan grande como en el mercado interno (60-53 por ciento), y el porcentaje de beneficios declarados era próximo a $42-51$ por ciento de los beneficios netos mundiales determinando que, las actividades internacionales de dichas empresas fueran vitales para sus éxitos. En 1974, la IBM primer fabricante multinacional estaba establecido en 126 países y tenían 274 mil empleados alrededor del mundo y más de 44 por ciento trabajaba en World Trade Corporation. Para un acercamiento elemental al tema en la actualidad revisar la geopolítica del 5G (Le Monde Diplomatique, 2020). 
legislativos ratificando el consentimiento libre, informado, revocable y de interpretación restrictiva que conlleva el amparo de los derechos humanos de acuerdo con las exigencias tecnológicas del siglo XXI.

Pese a que Argentina adhirió a la Convención para la Prevención y sanción del Delito de Genocidio el 9 de abril de 1956, con reservas, mediante el Decreto Ley 6.286, un reciente Proyecto de Reforma del Código Penal argentino (Borinsky, 2019) procura incluir, entre otras figuras penales, los delitos de genocidio como tipo penal autónomo y el de terrorismo. Pese al retraso legislativo en la materia y al disenso, cada vez más consenso sobre que la sociedad argentina contemporánea es una sociedad postgenocidio (Levy, 2009). Por ello generar una base jurídica exhaustiva que redunde en la introducción de prácticas estatales preventivas abarcando la norma que tutela el SEN constituye, una tarea pendiente en cuanto a las garantías de no repetición.

Uno de los países fundados durante el siglo XX luego de un genocidio es Israel. De modo que revisar ese aspecto del articulado legal israelí permite reconocer la necesidad de cambio de la reglamentación sobre estadísticas argentina.

\section{ENTORNO Y REGISTRO DE LA POBLACIÓN: EXPERIENCIA ISRAELÍ}

Tras la Segunda Guerra Mundial se fundó el Estado de Israel (14 de mayo de 1948) ${ }^{36}$ que heredó el sistema legal del gobierno británico ${ }^{37}$ aunque, las trasformaciones necesarias para la organización del nuevo país las inició el Consejo Estatal Provisional (14 de mayo de 1948-14 de febrero de 1949) mediante ordenanzas, entre otras, The Prevention of Terrorism Ordinance, 5708-1948. Las reformas prosiguieron con la Asamblea Constitucional, luego denominada primer Knesset (14 de febrero de 1949 - 20 de agosto de 1951) que como una de sus acciones más destacadas plasmó la Nazis and Nazi Collaborators (Punishment) Law, 5710, No. 64, 1950 que penalizó los crímenes contra el pueblo judío, contra la humanidad y los crímenes de guerra ocurridos en el contexto aludido. En el mismo sentido, The Crime of Genocide (Prevention and Punishment), Law 5710, 1950 a la vez que

${ }^{36}$ Véase la Declaración Fundacional del Estado de Israel y sus antecedentes (Declaración de Balfour de 1917 y Mandato a Palestina del Consejo de la Liga de Naciones de 1922).

${ }^{37}$ La Asamblea General de la ONU puso fin al mandato británico el 29 de noviembre de 1947 decidiendo la partición de dos Estados independientes, judío y árabe. Pero los palestinos apoyados por los países árabes independientes rechazaron la partición (Resolución 181/1947 de la Asamblea General de Naciones Unidas) y la noche del 29 al 30 de noviembre de 1947 comenzó la Guerra de la Independencia donde combatieron sobrevivientes de la Shoá y hubo seis mil muertos - uno por ciento de la población que equivale a las pérdidas que sufrió Francia durante la Primera Guerra Mundial- (Sternhell, 2013). Y fue referido anteriormente el concepto de nakba (15 de mayo de 1948). 
sanciona las conductas genocidas, protege a la población de potenciales políticas poblacionales segregacionistas por motivos de nacionalidad, etnia y religión.

En términos demográficos es importante revisar dicho entramado jurídico pues la sola existencia del Estado de Israel denuncia y se contrapone, a las políticas segregacionistas del régimen nazi (30 de enero de 1933 - 8 de mayo de 1945) y de sus aliados durante la Segunda Guerra Mundial (1 de septiembre de 1939 - 14 de agosto de 1945) que reconfiguró la geopolítica mundial.

De ahí que la ley migratoria postgenocidio conocida como Law of Return, 5710, No. 48, 1950 adquirió un carácter fundante en la configuración multicultural de la población israelí a la que se sumó, la norma sobre diversidad religiosa cuyas diferencias de criterios sobre los derechos a los cuales pueden acceder las mujeres motivaron la sanción temprana de la Women's Equal Rights Law, 5711, No. 68, 1951. Es decir, con la fundación del Estado de Israel, la autonomía religiosa heredada del Mandato Británico se transpuso quedando, el aspecto poblacional referido a matrimonios y divorcios bajo la jurisdicción de cada corte religiosa de Israel: para judíos la Corte Rabínica (Rabinical Court Judisdiccion (Marriage and Divorce) Law 5713, No. 64, 1953), para musulmanes la Corte Sharia (Qadis Law, 5221, No. 50, 1961), para drusos la Corte Drusa (The Druze Courts Law, 1962) y para cristianos la Corte de Israel específica para la comunidad cristiana con lo cual se cuenta con estadísticas sobre matrimonios y divorcios según religión, aunque para Francis Raday (1995) ${ }^{38}$ el estatuto de divorcio irradia desigualdad, incluso cuando se lo intenta regular mediante normas seculares como la mencionada ley sobre igualdad de derechos de la mujer. En el año 1965, el quinto Knesset (4 de septiembre de 1961-22 de noviembre de 1965) plasmó la Population Registry Law, 5727, No. 65, 1965 posicionando a Israel entre los más de sesenta países del mundo que a finales del decenio de 1960 gestionaban sus registros realizando, la copia de un formulario, codificado y perforado mediante computadoras de alta velocidad (Naciones Unidas, 1992: 72-75).

En efecto, con una base común a los registros implementados por Islandia, Bulgaria, Hungría y la exrepública Democrática Alemana y una treintena de países de la Unión Europea (Poulain y Herm, 2013) Israel centraliza la información en bancos de datos individualizables, aunque, las publicaciones estadísticas corresponden a compilaciones de conjunto. Es

${ }^{38}$ En los albores del siglo XXI se sancionó, la Civil Union Law for Citizens with no Religious Affiliation, 2010. 
importante revisar el caso israelíi $i^{39}$ pues el compromiso de administrar y actualizar el Registro de la Población lo asume el Ministerio del Interior en la Administración del Registro de la Población y, la producción estadística recae sobre la Oficina Central de Estadística, dependiente del Ministerio de Salud y Bienestar que compila las estadísticas habiendo creado, en 1956, la Comisión Nacional de Estadísticas Vitales y Sanitarias (Naciones Unidas, 1985: 16).

Todo registro de población consiste en un sistema de datos individualizado, es decir, un mecanismo para la inscripción constante, y/o la vinculación coordinada, de determinada información relativa a cada individuo de la población residente de un país o zona permitiendo determinar la dimensión y las características de la población a intervalos de tiempo dados.

Los registros de población se construyen a partir de un inventario de los habitantes de una zona y sus características el que debe actualizarse continuamente. Para localizar un acta de una persona particular o de un hogar o familia en un registro de población se elaboran índices por dirección de calles que facilitan, la inscripción del suceso en el registro asignado mediante un número personal único. Los registros se ocupan de la inscripción y certificación de los nacimientos y defunciones, la emisión de pasaportes y tarjetas de identidad, los cambios de residencia y del estado de residencia legal (por ejemplo, de un visado de turista a una residencia permanente). En efecto, la Population Registry Law, 5727, No. 65, 1965 instituye en su capítulo primero, la aplicabilidad de la norma a los residentes según: i) nombre y apellido; ii) nombre de los padres; iii) fecha y lugar de nacimiento; iv) sexo; v) grupo étnico; vi) religión; vii) estado personal (soltero, casado, divorciado, viudo); viii) nombre del cónyuge; ix) nombre, fecha de nacimiento, sexo de los hijos; $x$ ) nacionalidad/es presente/s y pasada/s; xi) dirección; xii) año de ingreso al país; xiii) fecha de inicio de la residencia.

En síntesis, el sistema de archivos e índices de un país se denomina "registro de la población" y tanto su organización, como su funcionamiento debe tener una base jurídica exhaustiva que redunda en la introducción de las prácticas estatales preventivas analizadas (Esquema 3).

${ }^{39}$ Israel y el MERCOSUR suscribieron un tratado de libre comercio el 18/12/2007 cuya vigencia comenzó a regir entre Israel-Uruguay el 23/12/2009; entre Israel-Paraguay el 24/3/2010; entre Israel-Brasil el 3/4/2010 y entre Israel-Argentina el 9/9/2011. 


\section{A MOdo de CONClusión: estadísticas POBlacionales Y PROCESO DE DES-CIVILIZACIÓN}

No es posible establecer con exactitud el momento en el cual, los seres humanos comenzaron a requerir de prácticas censales de algún tipo para reorganizar una especie superior basada en los censos que concentraría al "verdadero pueblo" (Gonnard, 1969: 49-59). Ni tampoco se puede precisar cuándo desarrollos tecnológicos como las computadoras presionaron hacia un crecimiento de las interdependencias y, correspondientemente, hacia una gran integración. Hubo un largo periodo inicial de experimentación abarcando tiempos de paz y de guerra e involucrando a gobernantes, empresarios, inventores, científicos, ingenieros. Sucede que los procesos de tecnificación y de civilización " $[\mathrm{N}]$ o son procesos planeados por haber surgido del entrelazamiento, la conjunción, la cooperación y la confrontación de muchas actividades planeadas" (Elias, 1998: 453).

Atendiendo a ese concepto es importante conocer que habría sido Herman Hollerith quien entre 1884 y 1896 desarrolló una máquina que sería elogiada por burócratas, ingenieros y estadísticos de diferentes latitudes por su eficacia para contar y calcular, en semanas, lo que a una persona le llevaría años. De modo que cuando la Oficina del Censo de los Estados Unidos patrocinó un concurso para encontrar el mejor dispositivo de conteo nadie se extrañó de su éxito.

Fue así como los cálculos del censo de 1890 se completaron con velocidad sin precedentes gracias a las perforadoras, clasificadoras y tabuladoras que les añadieron una nueva dimensión al censo debido a que, desde entonces podrían incluir un gran número de preguntas permitiendo a los gobiernos perfilar la población mediante los rasgos de su interés.

Si bien IBM fue fundada en 1896 por el inventor alemán Herman Hollerith como una empresa de tabulación de censos, cuando IBM y Alemania forjaron su alianza tecnológica y civilizatoria con el régimen nazi, el censo y el registro adquirieron otra dimensión pues se diseñó el censo racial, enumerando no sólo la filiación sino también, el linaje que se remonta a generaciones atrás, la que quedaba registrada en una tarjeta perforada que no sólo permitió contar a personas judías, sino que permitió identificarlas. Es efecto, cuando una persona judía fue hallada dentro de la población mediante una tarjeta denominada "cartas de conteo judío" se registró el lugar de nacimiento para procesarlas por separado y clasificarlas mediante veinticinco categorías de información indexadas y filtradas a través de treinta y cinco operaciones: por profesión, por residencia, por origen na- 
cional y demás, todo correlacionado con la información sobre registros de tierras, listas comunitarias y autoridades religiosas creando una nueva base de datos. Lo que surgió, entonces, fue profesión por profesión, ciudad por ciudad, la revelación de la presencia judía en el territorio para la segregación. Además, el Reich fue capaz de identificar a quienes, entre los judíos, serían los primeros "objetivos" para la confiscación, el arresto, el encarcelamiento y, en última instancia, expulsión. Los llamados Ostjuden, o judíos orientales, principalmente de Polonia, serían los primeros en llegar. Los contadores Hollerith se utilizaron a una tasa de segregación de 24 mil "cartas de conteo" por hora.

Como se dijo, la brecha temporal entre lo tecnológico y otras ramas del desarrollo en una sociedad, por un lado, y los cambios correspondientes a la estructura de la personalidad, por otro, es uno de los elementos principales cuando se enfoca la relación entre los procesos de civilización y tecnificación como el aquí analizado (Elias, 1998: 451-508).

Por ello cuando la «computadora electrónica» comenzó a incidir en el proceso de desarrollo de los países de América del Sur, a través del proceso de tecnificación se descubre a través de documentos históricos de la época, el sello de cruzada clerofascista con el que se identificaron los ejércitos americanos de entonces (Congreso de la Nación, 1966).

Sucede que la cristalización de procesos de cuantificación, tecnificación, desarrollo económico o formación de Estados tienen una autonomía limitada en el esquema del desarrollo total de la humanidad. Dichos hitos que indican una tendencia en el largo proceso de organización social en torno a las computadoras hoy reúnen los avances tecnológicos producto de los desarrollos procedentes de la telefonía, la radio y la televisión que han tenido una influencia civilizadora enorme al acercar a las personas de todas las regiones del mundo. Sin embargo, las crecientes interdependencias entre los implicados en los cambios producidos por los desarrollos tecnológicos y los procesos civilizatorios conllevan tensiones de integración y desintegración que dominan las figuraciones de los Estados y llegan al presente.

Como señala Norbert Elias en medio de las relaciones de tensión de muchos individuos cuyas acciones se orientan por planes y finalidades de corto plazo ocurre siempre que surge, un cambio no planeado del marco de referencia social que en el largo plazo va en determinada dirección. Es decir, hoy en día nadie se plantea cómo hacer para rodar un carro no si es viable o no internet. Eso en el ámbito de la praxis social. En la teoría de las ciencias se plantea una puja por establecer cuáles son los procesos o desa- 
rrollos sociales que establecen cambios orientados, pero no planeados. En dicha puja los conceptos 'progreso' y 'desarrollo' están en disputa.

Para Elias hasta que Darwin liberó "la idea de un desarrollo biológico de sus acciones teleológicas y metafísicas" no se logró comprender que el desarrollo social y "los progresos comprobables de la humanidad" aluden a "procesos no-intencionales pero explicables". La resistencia contra la idea darwiniana de un proceso evolutivo, pero sobre todo contra la procedencia de los humanos de unos antecesores similares a los simios se funda en que dicha innovación representó una herida narcisista como la que produjeron otras (Elias, 1998: 192-195). Pero además porque develó que no es posible pensar a los seres humanos como el fin último de la evolución biológica, al punto que persiste el problema de la explicación del orden secuencial de los cambios biológicos carentes de toda finalidad. Tal situación es algo similar a lo que sucede con "la fe en un desarrollo social preestablecido en dirección a lo que se registra, de acuerdo con los ideales propios, como progreso" aunque si la dirección es vista en el largo plazo hay hechos sociales que indican lo contrario. La aceleración del proceso de civilización disparó un movimiento de dirección opuesta, un movimiento hacia la des-civilización.

\section{BibLIOHEMEROGRAFIA}

\section{Oficiales}

Arcángel San Gabriel Comisión del Arma de Comunicaciones e Informática, Ejército Argentino, 2014, Reseña, Disponible en línea en la dirección: http://www. sangabriel.mil.ar/page12/index.html

Asamblea General, Naciones Unidas, 1947, Resolución 181. Plan de partición. Resolución aprobada sobre la base del informe de la comisión Ad Hoc encargada de estudiar la cuestión de Palestina.

Congreso de la Nación, 1966, VII Conferencia de Ejércitos Americanos, reservado, tomo I, Buenos Aires. (SHE).

Comando en Jefe del Ejército, 1967, Curso de planeamiento y programación, Secreto, Buenos Aires, EMGE. (SHE).

CEPAL, 2020, América Latina y el Caribe ante la pandemia del Covid-19. Efectos económicos y sociales. Informe $\mathrm{N}^{\circ} 1$, Naciones Unidas. Disponible en línea en la dirección: https://www.cepal.org/es/publicaciones/45337-america-latina-caribe-la-pandemia-covid-19-efectos-economicos-sociales .

EMGE, 1968, Sistema de computación automático de datos, RC-65-113, IGM. (SHE). 
De la Cuesta Ávila, José J., 2002, Desarrollo del sistema de computación de datos "SCD" en el Ejército Argentino, Documento de trabajo, Comisión de Comunicaciones e Informática 2002. Buenos Aires, EMGE. (SHE).

De la Cuesta Ávila, José J., 2005, "Sistema de comunicación de datos (SCD)". Revista de la Comisión del Arma de Comunicaciones "Arcángel San Gabriel", núm. 30.

Dirección Nacional del Sistema Argentino de Información Jurídica, 2015, Responsabilidad empresarial en delitos de lesa humanidad. Represión a trabajadores durante el terrorismo de Estado, Tomo I y II, Ministerio de Justicia y Derechos Humanos de la Nación, CABA.

INDEC, 2020, Apertura de propuestas en el rubro comercial: Impresión de formularios. Digitalización. Captura de datos. Visualización de datos del Censo Nacional de Población, Hogares y Viviendas, 24/7/2020. Disponible en línea en la dirección: https://www.youtube.com/watch?v=s0HtKUM1XTo\&feature=youtu.be

Información Legislativa, 1978, Decreto S 1.827. Autoriza al Ministerio de Defensa (Comando en Jefe de la Armada) a contratar la adquisición de un "Sistema de computación" a la firma IBM, del 11/8/1978 desclasificado el 24/4/2013. Disponible en línea en la dirección: http://servicios.infoleg.gob.ar/infolegInternet/verNorma.do;jsessionid=1E975AF1B8790BA81C63C0B0BECC3A30? id=212156

Información Legislativa, 1978, Decreto S 585, 9/3/1978. Designar en el Ministerio de Planeamiento, Subsecretario de Informática al Comodoro (R) D. Oscar Gregorio Vélez. Disponible en línea en la dirección: http://servicios.infoleg.gob. ar/infolegInternet/anexos/215000-219999/215713/norma.htm .

Información Legislativa, 1968, Ley 17.622, 25/1/1968. Disponible en línea en la dirección: http://servicios.infoleg.gob.ar/infolegInternet/anexos/20000-24999/24962/texact.htm

Información Legislativa, 1956, Decreto Ley 6.286. Adhesión a la Convención para la Prevención y sanción del Delito de Genocidio, 1956. Disponible en línea en la dirección: http://servicios.infoleg.gob.ar/infolegInternet/verNorma.do?id=202959

IPPDH, 2015, A 40 años del Cóndor. De las coordinaciones represivas a la construcción de las políticas públicas regionales en derechos humanos. Mercosur, Reunión de Altas Autoridades en Derechos Humanos y Cancillerías del Mercosur, ISBN: 978-987-46093-0-4.

Knesset, 1965, Population Registry Law, 5727, No. 65, 1965. Disponible en línea en la dirección: https://knesset.gov.il/review/data/eng/law/kns5_population_eng. pdf

IPPDH, 1965, Qadis Law, 5221, No. 50, 1961. Disponible en línea en la dirección: https://knesset.gov.il/review/data/eng/law/kns4_qadis_eng.pdf

IPPDH, 1953, Rabinical Court Judisdiccion (Marriage and Divorce) Law 5713, No. 64, 1953. Disponible en línea en la dirección: https://knesset.gov.il/review/ data/eng/law/kns2_rabbiniccourts_eng.pdf 
IPPDH, 1951, Women's Equal Rights Law, 5711, No. 68, 1951. Disponible en línea en la dirección: https://knesset.gov.il/review/data/eng/law/kns1_women_eng.pdf

IPPDH, 1950, Nazis and Nazi Collaborators (Punishment) Law, 5710, No. 64, 1950. Disponible en línea en la dirección: https://knesset.gov.il/review/data/eng/ law/kns1_nazis_eng.pdf

IPPDH, 1950, The Crime of Genocide (Prevention and Punishment), Law 5710, 1950. Disponible en línea en la dirección: https:/laws4me.com/wp-content/ uploads/Laws/Israel/Crime_of_Genocide.pdf .

IPPDH, 1950, Law of Return, 5710, No. 48, 1950. Disponible en línea en la dirección: https://knesset.gov.il/review/data/eng/law/kns1_return_eng.pdf

IPPDH, 1951, The First Knesset. 14/2/1949-20/8/1951. Disponible en línea en la dirección: https://knesset.gov.il/review/ReviewPage.aspx?lng=3\&kns=1

Ministerio de Cultura y Educación, 1977, Subversión en el ámbito educativo. Conozcamos a nuestro enemigo, Buenos Aires, Ministerio de Cultura y Educación.

Ministerio de Defensa, s/f. Listas negras de artistas, músicos, intelectuales y periodistas. Disponible en línea en la dirección: https://www.argentina.gob.ar/sites/ default/files/listasnegras.pdf

Ministry of Foreign Affair, 1948, Declaration of Establishment of State of ISrael, 14/5/1948. Disponible en línea en la dirección: https://mfa.gov.il/MFA/ForeignPolicy/Peace/Guide/Pages/Declaration\%20of\%20Establishment $\% 20$ of $\% 20$

State\%20of\%20Israel.aspx

Ministry of Foreign Affairs, 1948, The Prevention of Terrorism Ordinance, 5708, 23/9/1948. Disponible en línea en la dirección: https://mfa.gov.il/MFA/MFA-Archive/1900-1949/Pages/Prevention\%20of\%20Terrorism\%20Ordinance $\% 20$ No\%2033\%20of\%205708-19.aspx

Ministerio de Relaciones Exteriores y Culto, 1981, Nota n "S" de la República de la Haya, 20/8/1981. Disponible en línea en la dirección: http://desclasificacion.cancilleria.gov.ar/userfiles/documentos//OEAONUEXP20313/80AH008209_043. pdf_

Organización de Estados Americanos, 2007, Sistema de Información sobre Comercio Exterior (SICE), 18/12/2007. Tratado de Libre Comercio MERCOSUR-ISrael. Disponible en línea en la dirección: http://www.sice.oas.org/Trade/MER ISR/Index_s.asp

UNESCO, 2007, Informe Situacional de Privacidad y Acceso a la Información en América Latina, Francia, ONG Alfa Redi y Biblioteca Nacional del Perú.

UNESCO, 1978a, La politica científica y tecnológica en América Latina y el Caribe. Quinta reunión de la Conferencia permanente de dirigentes de los consejos nacionales de política científica y de investigación de los Estados Miembros de América Latina y del Caribe, Quito, Ecuador, 13 al 18 de marzo de 1978, París, $4, \mathrm{n}^{\circ} 42$. 
UNESCO, 1978b, "Capítulo I. Situación actual y perspectivas futuras del empleo de la informática: experiencias en la elaboración de políticas y estrategias nacionales en materia de informática", en Estrategias y políticas en materia de informática (Documento principal de trabajo), SC-78/SPIN/3/ IBI/SPINGR/153 (SC.78/Conf.210/Col.5), Disponible en línea en la dirección: https://unesdoc.unesco.org/in/documentViewer.xhtml? $\mathrm{v}=2.1 .196 \& \mathrm{i}-$ $\mathrm{d}=\mathrm{p}$ : :usmarcdef_0000030212_spa\&highlight=Organizaci $\% \mathrm{C} 3 \% \mathrm{~B} 3 \mathrm{n} \% 3 \mathrm{~A} \% 20$ $\% 22$ Oficina $\% 20$ Intergubernamental $\% 20$ para $\% 201 \mathrm{a} \% 20$ Inform $\% \mathrm{C} 3 \% \mathrm{~A} 1$ tica\%22\&file=/in/rest/annotationSVC/DownloadWatermarkedAttachment/attach import 5a27b52a-b9c8-45cd-acbb-2d0b458e4d0a\%3F \%3D030212spab.pdf\&locale $=$ es\&multi=true\&ark=/ark:/48223/pf0000030212_spa/PDF/030212spab. pdf\#\%5B\%7B\%22num\%22\%3A224\%2C\%22gen\%22\%3A $0 \% 7 \mathrm{D} \% 2 \mathrm{C} \% 7 \mathrm{~B} \%$ 22 name $\% 22 \% 3 \mathrm{~A} \% 22 \mathrm{XYZ} \% 22 \% 7 \mathrm{D} \% 2 \mathrm{Cnull} \% 2 \mathrm{Cnull} \% 2 \mathrm{C} 0 \% 5 \mathrm{D}$

UNESCO, IBI, 1979, Conferencia intergubernamental sobre las estrategias y las políticas en materia de informática. Informe final. SC/MD/63, Paris. Disponible en línea en la dirección: https://unesdoc.unesco.org/ark:/48223/pf0000035616 spa?posInSet $=5 \&$ queryId=N-EXPLORE-cc509ca0-420f-468e-84ec-a305d8c6f$1 \mathrm{ba}$

United Nations, 9/12/1948, Treaty Colleccions, Chapter IV, 1, Human Rights, Convention on the Prevention and Punishment of the Crime of Genocide, Paris, pp.1-12. Disponible en línea en la dirección: https://treaties.un.org/doc/Publication/MTDSG/Volume\%20I/Chapter\%20IV/IV-1.en.pdf

United Nations, 20/12/2006, Treaty Colleccions, Chapter IV, 16, Human Rights, International Convention for the Protection of All Persons from Enforced Disappearance, New York. Disponible en línea en la dirección: https://treaties.un.org/ Pages/ViewDetails.aspx?src=TREATY\&mtdsg_no=IV-16\&chapter=4\&clang $=$ en

United State of America. Freedom of Information Act. 5 USC 552, Disponible en línea en la dirección: https://uscode.house.gov/view.xhtml?req=(title:5\%20 section:552\%20edition:prelim) $\% 20 \mathrm{OR} \% 20$ (granuleid:USC-prelim-title5-section552)\&f=treesort\&edition $=$ prelim\&num $=0 \& j u m p T o=$ true

\section{Periódicos, comunicaciones}

Ámbito, 14/10/2020 (b), El presidente de China pidió a sus tropas que se «preparen para la guerra», https://www.ambito.com/mundo/china/el-presidente-pidiosus-tropas-que-se-preparen-la-guerra-n5140384 .

Clarín, 2/11/2020, China lanza su primer censo tras abandonar la política del "hijo único". Disponible en línea en la dirección: https://www.clarin.com/agencias/afp-china-lanza-primer-censo-abandonar-politica-hijo-unico-_0_k6z3Q7srp. $\mathrm{html}$

El tempo (a), Manaus, 198-?, "A conexão chilena: como computadores, universidades, generais e a DINA estão ligados entre si, por debaixo do balaio", en Memoria Abierta y Servicio Paz y Justicia de Argentina (SERPAJ). 
El tempo (b), Manaus, 198-?, "Você venderia um computador a Pinochet?: a internacional da repressão no Cono Sul: terceira de uma série", en Archivos de Memoria Abierta y Servicio Paz y Justicia de Argentina (SERPAJ).

Le Monde Diplomatique, octubre 2020, Reseña: La lucha por el control de las tecnologías de Internet. Geopolítica del 5G. Disponible en línea en la dirección: https://www.eldiplo.org/256-las-luchas-por-la-tierra/geopolitica-del-5g/

Grushka, Carlos, 11/9/2019, Carta del presidente de la Asociación de Estudios de Población de la Argentina al director del Instituto Nacional de Estadísticas y Censos (comunicación).

Maisuls, Guido, 12/10/2020, Haciendo historia: Un carguero de los Emiratos Árabes Unidos en el puerto de Haifa. Disponible en línea en la dirección: https:// identidades.com.ar/haciendo-historia-un-carguero-de-los-emiratos-arabes-unidos-en-el-puerto-de-haifa/

Sadeque, Samira, 2/11/2020, China acusada de violar DDHH dentro y fuera de su territorio, publicado por Inter Press Service, disponible en línea en la dirección: http://www.ipsnoticias.net/2020/01/china-acusada-violar-ddhh-dentro-territorio/

Télam, 30/06/2020, LEY. China promulgó la controvertida Ley de Seguridad de Hong Kong. Disponible en línea en la dirección: https://www.telam.com.ar/notas/202006/483393-china-hong-kong-ley-de-seguridad.html

UN Watch, 12/2/2020, La ONU publica lista negra anti-Israel, alimentando a la campaña de Boicot, Desinversión y Sanciones. Disponible en línea en la dirección: https://unwatch.org/528542-2/

\section{Webinarios}

Férez, Manuel y Yonathan Nowogrodski, 2021, Claves del Conflicto Palestino Israelí. Curso de estudios judíos de Chile.

López Göttig, Ricardo, 10/6/2020, Historia y libertad: nacionalismo y antisemitismo en Argentina, Conferencias UCEMA.

Nakamae, Takahiro, 20/10/2020, Japón-Argentina: reflexiones sobre la relación bilateral. Encuentro con el Embajador, Buenos Aires, Georgetown, UCEMA.

Ronen, Galit, 7/7/2020, "La experiencia de Israel", en Ciclo La respuesta del mundo al Covid-19, UCEMA.

Tang, Audrey, 2019, Digital Social Innovation, Digital Minister of Taiwan, Actividad organizada por Fundación Naumann y RELIAL, UCEMA.

Zanatta, Loris, 16/6/2020, El retorno del Estado entre mesiánicos y apocalípticos, UCEMA Talks. 


\section{Referencias bibliográficas}

Adler, Emmanuel, 1988, "State Institutions, Ideology, and Autonomous Technological Development: Computers and Nuclear Energy in Argentina and Brazil", en Latin American Research Review, vol. 23, No. 2., pp. 59-90.

Adler, Emmanuel, 1987, “The Quest for Technological Autonomy in Argentina and Brazil", en The Power of Ideology. The Regents of the University of California, Library of Congress Cataloging in Publication Data, pp. 223-237.

Agamben, Giorgio, 2007, Estado de excepción. Adriana Hidalgo editora, Buenos Aires.

Arendt, Hannah, 2008, Sobre la revolución. Alianza Editorial. Buenos Aires.

Arriola, María Teresa, Platzer, Emilio y Lago, María Eugenia, 2018, "El uso de nuevas tecnologías para la producción de estadísticas públicas. Un camino recorrido y por recorrer", en Población de Buenos Aires, año 15, No. 27, pp. 63-85.

Auschwitz Institute for the Prevention of Genocide and Mass Atrocities, s./f., "Building Resilience to Genocide. Ten Practical Measures", in Policy Brief in Prevention, Disponible en línea en la dirección: http://www.auschwitzinstitute.org/ wp-content/uploads/2016/01/AIPR-Brief-Building-Resilience-to-Genocide.pdf .

Bernetti, Jorge Luis y Puiggrós, Adriana, 1993, "De la guerra a la pedagogía (1943-1949)", en Peronismo: cultura política y educación (1945-1955), pp. 4951, Buenos Aires, Editorial Galerna.

Bernetti, Jorge Luis y Puiggrós, Adriana, 1993, "El escenario educativo de una fundación", en Peronismo: cultura política y educación (1945-1955), pp. 15-70, Buenos Aires, Editorial Galerna.

Bilbao, Lucas y Ariel Lede, 2016, Profeta del genocidio. El vicariato castrense y los diarios del obispo Bonamín en la última dictadura. Buenos Aires, Sudamericana, http://profetadelgenocidio.com.ar/

Black, Edwin, 2001, IBM and the Holocaust: The Strategic Alliance between Nazi Germany and America's Most Powerful Corporation. New York, Crown.

Bongaarts, John y Greenhalgh, Susan 1985, "An alternative to the one-child policy in China", in Population and Development Review 11(4): 585-617.

Borinsky, Mariano, 2019, "Genocidio en el nuevo Código Penal”, en Compromiso, No. 73, año 12, mayo-agosto.

Borches, Carlos y Carnota, Raúl, 2011, "Misioneros entre gentiles. Los primeros pasos de la investigación operativa en Argentina"; en Velasco, María y Venture1li, Nicolás (ed.), Selección de trabajos de las XXI Jornadas de Epistemología e Historia de la Ciencia (Córdoba: Área Lógico-Epistemológica de la Facultad de Filosofía, UNC, ISBN 978-950-33-0919-3).

Cancelado Franco, Henry, 2020, "De la masacre de Nanjing a la nueva Ruta de la Seda: geopolítica y geoeconomía a comienzos del siglo XXI", en Revista Rela- 
ciones Internacionales, Estrategia y Seguridad, 15(1), pp. 31-42DOI: https://doi. org/10.18359/ries.4258.

Cardenal, Juan Pablo, 2020, Propaganda china para un escenario post Covid-19. Buenos Aires, Centro para la Apertura y el Desarrollo de América Latina.

Centro de Estudios sobre Genocidio (s./f.), Base de datos online de crímenes de Estado. Disponible en línea en la dirección: http://crimenesdeestado.untref.edu.ar/ busqueda-avanzada .

Centro de Estudios Sociales, 2007, Informe sobre la situación de los detenidos-desaparecidos judios durante el genocidio perpetrado en Argentina 19761983. Ciudad de Buenos Aires, DAIA.

Della Pergola, Sergio, 2016, "Entre ciencia y ficción: notas sobre la demografía de la Shoá", en Revista Mexicana de Ciencias Politicas y Sociales, Universidad Nacional Autónoma de México, Nueva Época, Año LXI, núm. 228, pp. 211-234. Disponible en línea en la dirección: https:/www.sciencedirect.com/science/article/pii/S0185191816300460.

De Miguel Castaño, Adoración, 1983, Derecho a la información frente al derecho a la intimidad. Su incidencia en el sistema de información estadística. Madrid, Instituto Nacional de Estadística.

Demopædia, 1959, Diccionario demográfico multilingüe, Disponible en línea en la dirección: http://www.demopaedia.org/tools/spip.php?page=generate_dictionary\&edition $=\mathrm{es}-\mathrm{i} \&$ format $=\mathrm{html}$.

De Souza Neves, Margarida, Silvia Ilg Byington y von Staa, Arndt, 2015, "El B-205 en la PUC-Río: historia y memoria de la primera computadora empleada en una universidad brasileña”, en Rodríguez Leal, Luis Germán y Carnota, Raúl. Historias de la Informática en América Latina y el Caribe: inicios, desarrollos y rupturas. Buenos Aires, Fundación Telefónica, Editorial Ariel, pp. 66-81.

Diaz de Guijarro, Eduardo, Baña, Beatriz, Borches, Carlos y Carnota, Raúl, 2015, Historia de la Facultad de Ciencias Exactas y Naturales, Ciudad de Buenos Aires, Eudeba.

Domingo, Andreu, 2008, Descenso literario a los infiernos demográficos. Anagrama, Barcelona.

Elias, Norbert, 1998, “Tecnificación y civilización”, en La civilización de los padres y otros ensayos, Bogotá, Norma, pp. 449-508.

Elias, Norbert, 1998, "Hacia una teoría de los procesos sociales", en La civilización de los padres y otros ensayos, Bogotá, Norma, pp. 139-197.

Feierstein, Daniel, 2016, Introducción a los estudios sobre genocidio. FCE, Eduntref, Ciudad Autónoma de Buenos Aires.

Elias, Norbert, 2014, El genocidio como práctica social. Entre el nazismo y la experiencia argentina, Ciudad de Buenos Aires, FCE. 
Feng, Wang, Cai Yong y Gu, Baochang, 2012, "Population, Policy, and Politics: How Will History Judge China's One-Child Policy?", in Population and Development Review, 38 (Supplement): 115-129.

Foucault, Michel, 1992, Genealogía del racismo. De la guerra de las razas al racismo de Estado, Madrid.

Greenhalgh, Susan, 2008, Just One Child: Science and Policy in Deng's China. University of California Press.

Gonnard, René, 1969, Historia de las doctrinas de la población, Santiago de Chile, Centro Latinoamericano de Demografía.

Gómez, Luz, 2019, Diccionario de islam e islamismo, Madrid, Editorial Trotta.

Goñi, Uki, 2017, La auténtica Odessa. Fuga nazi a Argentina. Ciudad de Buenos Aires: Ariel.

Jacovkis, Pablo, 2014, "Manuel Sadosky y su impacto en la ciencia y en la política argentina", en Manuel Sadosky. El sabio de la tribu, Buenos Aires, Libros del Zorzal.

Jacovkis, Pablo, 2013, De Clementina al siglo XXI: breve historia de la computación en la Facultad de Ciencias Exactas y Naturales de la Universidad de Buenos Aires, Buenos Aires, Eudeba

Kligman, Gail, 1998, The Poltics of Duplicity. Controlling Reproduction in Ceausescu's Romania. California, University of California Press.

Korte, Hermann, 1998, "Mirada sobre una larga vida. Norbert Elias y la teoría de la civilización", en Elias, Norbert, La civilización de los padres y otros ensayos, Norma, Bogotá, pp. 31-55.

Koselleck, Reinhart, 2001, Los estratos del tiempo: estudios sobre la historia, Barcelona, Paidós.

Levy, Guillermo, 2009, "Genocidio y Sociedades Posgenocidas", en Sitios de memoria: experiencias y desafios. Cuaderno I. Ciudad de Buenos Aires, Archivo Nacional de la Memoria, Red Federal de Sitios de Memoria, Secretaría de Derechos Humanos del Ministerio de Justicia, Seguridad y Derechos Humanos de la Nación.

Llorens, Emilio y Correa Ávila, Carlos, 1948, Demografía argentina. Esbozo de una política demográfica, Buenos Aires, FCE, UBA.

López, Ernesto, 1985, "Doctrinas Militares en Argentina: 1932-1980”, en Moneta, Carlos, López, Ernesto y Aníbal Romero, La reforma militar, Buenos Aires, Legasa, pp. 103-143.

López Göttig, Ricardo, 2019, Origen, mitos e influencias del antisemitismo en el mundo, Ciudad de Buenos Aires, Fundación Cadal, disponible en línea en la dirección: https://www.cadal.org/libros/pdf/Origen-Mitos-Influencias-Antisemitismo_Ricardo-Lopez-Gottig.pdf

Lozada, Martin, 2014, "Los dispositivos políticos del genocidio", en Derecho Penal y Criminología, año IV, 4:31-43. 
Masciadri, Viviana, 2021, "Registros de población y sistemas estadísticos: dos experiencias", en XI Congreso Nacional y XI Latinoamericano de Sociología Jurídica (SASJU) "De la excepción a la regla. La inconsistencia del discurso jurídico actual", Facultad de Derecho, UNR (en prensa).

Masciadri, Viviana, 2018, "Elementos para revisar competencias en materia de protección de datos en los sistemas estadísticos de los Estados Miembros del MERCOSUR", en Revista MERCOSUR de politicas sociales, vol. 2, pp.112-131, https://doi.org/10.28917/ism.2018-v2.

Masciadri, Viviana, 2017, "Explorando el pasado reciente: servicios estadísticos de las Fuerzas Armadas Argentinas conexos a la Ley 17.622", en Revista de Estudios sobre Genocidio, año 8, vol. 12, pp.132-143.

Masciadri, Viviana, 2013, "Nombre y apellido o razón social, domicilio y rama de actividad: ¿deben o no exceptuarse del secreto estadístico? Una revisión comparativa", en Espacios Públicos, 16(37), pp. 141-174.

Memoria Abierta, s./f., Las leyes de la dictadura. Disponible en línea en la dirección: www.lasleyesdeladictadura.com.ar/index.php?a=PublicView\&name=LeyesPublic .

Mignone, Emilio, 2013. Iglesia y dictadura. Buenos Aires, Coligue.

Monteiro Fernández, Jorge, 2015, “Testimonio de una vida entretejida con la Política Nacional de Informática de 1970 a 1990”, en Rodríguez Leal, Luis Germán y Carnota, Raúl. Historias de la Informática en América Latina y el Caribe: inicios, desarrollos y rupturas. Buenos Aires, Fundación Telefónica, Editorial Ariel, pp. 244-250.

Naciones Unidas, 1992, Manual de sistemas y métodos de estadísticas vitales. Volumen I: aspectos jurídicos, institucionales y técnicos. Serie F No. 35, New York.

Negretto, Gabriel, 1994, El problema de la emergencia en el sistema constitucional, Buenos Aires, Ábaco.

O’Donnell, Guillermo, 2009, El estado burocrático autoritario. Buenos Aires, Prometeo.

Périès, Gabriel, 2009, "De Argelia a la Argentina: estudio comparativo sobre la internacionalización de las doctrinas militares francesas en la lucha anti-subversiva. Enfoque institucional y discursivo", en Izaguirre, Inés (comp.) Lucha de clases, guerra civil y genocidio en la Argentina. 1973-1983. Buenos Aires: Eudeba.

Poulain, Michel y Herm, Anne, 2013, "Le registre de population centralisé, source de statistiques démographiques en Europe", in Population 2, vol. 68, p. 183-212. DOI 10.3917/popu.1302.0215.

Poulain, Michel y Herm, Anne, 1985, Manual de sistemas y métodos de estadísticas vitales. Volumen II: examen de las prácticas nacionales. Serie F No. 35, New York.

Seltzer, William, 1998, "Population Statistics, the Holocaust, and the Nuremberg Trials", in Population and Development Review, 24(3):511-552. 
Seltzer, William y Summer, Margo Anderson, 2001, "The Dark Side of Numbers: The Role of Population Data Systems in Human Rights Abuses", in Social Research, vol. 68 , No. 2.

Senkman, Leonardo, 1989, El antisemitismo en la Argentina. Buenos Aires: Centro Editor de América Latina.

Sternhell, Zeev, 2013, Los orígenes de Israel. Las raices profundas de una realidad conflictiva. Buenos Aires, Le Monde diplomatique, Capital Intelectual.

Raday, Francis, 1995, "Religion, Multiculturalism and Equality: the Israelí Case", in Israel Yearbook on Human Rights, 193-241. Disponible en línea en la dirección: https://main.knesset.gov.il/EN/Pages/SearchResults.aspx?q=equal\%20civil\%20 of $\% 20$ woman

Ritter, Joaquim, Karlfried, Gründer y Gottfried, Gabriel, 1998, Historisches Wörterbuch der Philosophie, Basel, Wissenschaftliche Buchgesellschaft Darmstadt, Band 10: St-T; 12: W-Z.

Rubiolo, Florencia, 2021, El conflicto del Mar de China Meridional en clave geopolítica. Disponible en línea en la dirección: https://ri.conicet.gov.ar/handle/11336/80265.

Valderrama, Fernando, 1995. Historia de la UNESCO, Paris.

Vetta, Atam y Courgeau, Daniel, 2003, "Comportements démographiques et génétique du comportement", en Population, 4, vol. 58,| pp. 457-488, disponible en línea en la dirección: https://www.cairn.info/revue-population-2003-4-page-457. htm .

Zanatta, Loris, 2005, Del estado liberal a la nación católica. Iglesia y Ejército en los orígenes del peronismo. 1930-1943. Bernal, Universidad Nacional de Quilmes.

\section{RESUMEN CURRICULAR DE LA AUTORA}

\section{Viviana Masciadri}

Doctora en Demografía por la Universidad Nacional de Córdoba.Actualmente se desempeña como investigadora en el Centro de Investigaciones y Estudios sobre Cultura y Sociedad (CIECS), Consejo Nacional de Investigaciones Científicas y Técnicas (CONICET)/Universidad Nacional de Córdoba (UNC), Valparaíso s/n Ciudad Universitaria, Córdoba.

Dirección electrónica: v.masciadri@gmail.com

Registro ORCID: orcid.oerg/000-0003-0550-5916 
Estadísticas poblacionales: marco jurídico, violación de derechos humanos, entorno gubernamental ... / V. MASCIADRI

Anexo 1. Listado de sentencias de crímenes de Estado calificados como genocidio. Argentina, 2004-2019

\begin{tabular}{|c|c|c|c|c|c|}
\hline Nombre & Fecha & Tribunal & $\begin{array}{l}\text { Calificación } \\
\text { legal }\end{array}$ & $\begin{array}{l}\text { Conceptualización } \\
\text { histórica }\end{array}$ & $\begin{array}{c}\text { Campo de } \\
\text { concentración / Objeto } \\
\text { de la causa }\end{array}$ \\
\hline $\begin{array}{l}\text { Causa n }{ }^{\circ} 76000073 / 2011 \text { "Vargas, Antonio Orlando y otros s/ } \\
\text { privación ilegal de libertad, imposición de tortura, homicidio } \\
\text { agravado por alevosía y por el concurso de dos o más } \\
\text { personas." }\end{array}$ & $29 / 05 / 14$ & $\begin{array}{l}\text { Tribunal Oral Federal- } \\
\text { Jujuy }\end{array}$ & Genocidio & Genocidio & $\begin{array}{l}\text { UNIDAD PENAL DE } \\
\text { VILLA GORRITI } \\
\text { (JUJUY) }\end{array}$ \\
\hline $\begin{array}{l}\text { Causa N } N^{0} 10630 / 2009 \text { "Almirón, Miguel Ángel y otros } \\
\text { s/privación ilegal de la libertad (art. } 144 \text { bis inc. 1) e } \\
\text { imposición de tortura (art. } 144 \text { ter inc.1)" }\end{array}$ & $18 / 02 / 15$ & $\begin{array}{l}\text { Tribunal Oral Federal } \\
\quad N^{\circ} 1 \text { - La Plata }\end{array}$ & Genocidio & Genocidio & $\begin{array}{c}\text { Comisaría 1 }{ }^{\text {a }} \text { de Junín } \\
\text { (Buenos Aires), } \\
\text { Unidad Penal (En } \\
\text { construcción) (Buenos } \\
\text { Aires), } \\
\text { Destacamento } \\
\text { "Morse" (Buenos } \\
\text { Aires), Unidad } \\
\text { Regional de Junín } \\
\text { (Buenos Aires) } \\
\text { /Almirón }\end{array}$ \\
\hline $\begin{array}{l}\text { Causa N} 1103 / 11 \text { TO1 "Fracassi, Eduardo René y otros s/ } \\
\text { privación ilégitima de la libertad (Artículo144 BIS, inciso } 1^{\circ} \text { ) } \\
\text { Querellante: Secretaría de Derechos Humanos Ministerio de } \\
\text { Justicia, Seguridad y Derechos Humanos de la Nación y } \\
\text { otros" }\end{array}$ & $25 / 11 / 15$ & $\begin{array}{l}\text { Tribunal Oral Federal- } \\
\text { Bahía Blanca }\end{array}$ & Genocidio & Genocidio & \begin{tabular}{|c} 
Base de Infantería de \\
Marina "Baterías" \\
(Batería VII) (Buenos \\
Aires), Buque "9 de \\
Julio", \\
Policía de \\
Establecimientos \\
Navales (Base Naval \\
"Puerto Belgrano") \\
(Buenos Aires)/ \\
Francassi
\end{tabular} \\
\hline $\begin{array}{l}\text { Causa N FLP 91133453/2013/TO1 "Etchecolatz, Miguel } \\
\text { Osvaldo y otros s/ infracción al artículo } 144 \text { bis inc. } 1^{\circ} \mathrm{y} \\
\text { último párrafo" }\end{array}$ & $23 / 03 / 16$ & $\begin{array}{l}\text { Tribunal Oral Federal } \\
\quad N^{\circ} 1 \text { - La Plata }\end{array}$ & Genocidio & Genocidio & $\begin{array}{l}\text { NO ESPECIFICADO/ } \\
\text { SE DESCONOCE }\end{array}$ \\
\hline $\begin{array}{l}\text { FPA 13000001/2012/TO2 "CÉPARO, ATILIO RICARDO } \\
\text { SOBRE INF. ART. } 144 \text { BIS EN CIRC. ART. } 142 \text { INC. 1, } 2 \text {, } \\
3,5 \text { " }\end{array}$ & $08 / 10 / 16$ & $\begin{array}{l}\text { Tribunal Oral Federal- } \\
\text { Paraná }\end{array}$ & Genocidio & Genocidio & $\begin{array}{l}\text { NO ESPECIFICADO/ } \\
\text { SE DESCONOCE }\end{array}$ \\
\hline $\begin{array}{l}\text { Causa N 33000200/TO1/2006 “DOMATO, HORACIO } \\
\text { RAFAEL S/ASOCIACIÓN ILICITA EN CONCURSO } \\
\text { REAL CON PRIVACIÓN ILEGÍTIMA DE LA LIBERTAD } \\
\text { PERSONAL, ETC.”. }\end{array}$ & $16 / 12 / 16$ & $\begin{array}{l}\text { Tribunal Oral Federal- } \\
\text { Formosa }\end{array}$ & Genocidio & Genocidio & $\begin{array}{l}\text { REGIMIENTO DE } \\
\text { INFANTERÍA DE } \\
\text { MONTE } 29 \\
\text { (FORMOSA) /idem }\end{array}$ \\
\hline $\begin{array}{l}\text { "ARRILLAGA, Alfredo Manuel - MARQUIEGUI, Leandro } \\
\text { Edgard s/Homicidio calificado" }\end{array}$ & $19 / 04 / 17$ & $\begin{array}{l}\text { Tribunal Oral Federal - } \\
\text { Mar del Plata }\end{array}$ & $\begin{array}{c}\text { Lesa } \\
\text { Humanidad }\end{array}$ & Genocidio & $\begin{array}{c}\text { EL VESUBIO } \\
\text { (BUENOS AIRES), } \\
\text { Comisaría } 4^{\circ} \text { (CABA), } \\
\text { Agrupación de } \\
\text { Artillería } \\
\text { de Defensa Aérea } 601 \\
\text { / idem } \\
\end{array}$ \\
\hline $\begin{array}{l}\text { "BOCCALARI GUSTAVO ABEL S/ INF. ART. } 144 \text { TER } 1^{\circ} \\
\text { PÁRRAFO - SEGÚN LEY 14.616; INF. ART. } 144 \text { BIS INC. } \\
1 \text { Y ÚLTIMO PÁRRAFO - SEGÚN LEY 14.616 EN } \\
\text { FUNCIÓN DEL ART. } 142 \text { INC. 1 - LEY 20.642; } \\
\text { HOMICIDIO AGRAVADO CON ENSAÑAMIENTO- } \\
\text { ALEVOSÍA" }\end{array}$ & $05 / 05 / 17$ & $\begin{array}{l}\text { Tribunal Oral Federal - } \\
\text { Bahía Blanca }\end{array}$ & Genocidio & Genocidio & $\begin{array}{l}\text { Brigada de } \\
\text { Investigaciones y } \\
\text { Delegación } \\
\text { Cuatrerismo/idem }\end{array}$ \\
\hline $\begin{array}{l}\text { BAEZ MALBEC, MIGUEL ANGEL Y OTROS } \\
\text { s/PRIVACION ILEGAL DE LIBERTAD (ART.144 BIS } \\
\text { INC.1) y IMPOSICION DE TORTURA (ART.144 } \\
\text { TER.INC.1) - QUERELLANTE: ASAMBLEA } \\
\text { PERMANENTE DE LOS DERECHOS HUMANOS Y } \\
\text { OTROS }\end{array}$ & $14 / 06 / 17$ & $\begin{array}{c}\text { Tribunal Oral Federal } 2 \\
\text { - Mendoza }\end{array}$ & Genocidio & Genocidio & $\begin{array}{l}\text { Megacausa San Rafael } \\
\text { / idem }\end{array}$ \\
\hline $\begin{array}{l}\text { Principal en Tribunal Oral TO01 - IMPUTADO: BAEZ } \\
\text { MALBEC, MIGUEL ANGEL Y OTROS s/PRIVACION } \\
\text { ILEGAL DE LIBERTAD (ART.144 BIS INC.1) y } \\
\text { IMPOSICION DE TORTURA (ART.144 TER.INC.1) - } \\
\text { QUERELLANTE: ASAMBLEA PERMANENTE DE LOS } \\
\text { DERECHOS HUMANOS Y OTROS }\end{array}$ & $02 / 06 / 17$ & $\begin{array}{c}\text { Tribunal Oral Federal } 2 \\
\text { - Mendoza }\end{array}$ & Genocidio & Genocidio & $\begin{array}{l}\text { Municipio San Rafael } \\
\text { - Mendoza, Infantería, } \\
\text { Casa departamental } \\
\text { (Tribunales o Colegio } \\
\text { de Martilleros), } \\
\text { Bomberos, Bodega } \\
\text { Gadín, D2 / idem } \\
\end{array}$ \\
\hline
\end{tabular}


Anexo 1. Continuación

\begin{tabular}{|c|c|c|c|c|c|}
\hline Nombre & Fecha & Tribunal & $\begin{array}{c}\text { Calificación } \\
\text { legal }\end{array}$ & $\begin{array}{c}\text { Conceptualización } \\
\text { histórica }\end{array}$ & $\begin{array}{c}\text { Campo de } \\
\text { concentración / Objeto } \\
\text { de la causa }\end{array}$ \\
\hline $\begin{array}{l}\text { "MENÉNDEZ SÁNCHEZ, Luciano B. y Otros s/ Inf. Art. } \\
144 \text { ter C.P." y sus acumulados No 077-M, 091-M, 096-M, } \\
\text { 098-G, 099-M, 105-F, 106-M, 108-M, 109-M, 110-M, 111- } \\
\text { M, 112-C, 14000800/2012 y 14000820/2010 }\end{array}$ & $26 / 07 / 17$ & $\begin{array}{c}\text { Tribunal Oral Federal } 1 \\
\text { - Mendoza }\end{array}$ & Genocidio & Genocidio & $\begin{array}{l}\text { DEPARTAMENTO } \\
\text { DE } \\
\text { INFORMACIONES } \\
\text { DE LA POLICÍA DE } \\
\text { MENDOZA (D-2) } \\
\text { o JEFATURA DE } \\
\text { POLICÍA DE } \\
\text { MENDOZA } \\
\text { (MENDOZA) } / \text { idem } \\
\end{array}$ \\
\hline $\begin{array}{l}\text { "FERRER, José Néstor; NERONE, Rolando Oscar; y } \\
\text { GUTIÉRREZ, Oscar Roberto s/privación ilegal de la libertad } \\
\text { agravada por mediar violencia o amenazas y homicidio } \\
\text { agravado por alevosía" y "ENCISO, César Alejandro } \\
\text { s/privación ilegal de la libertad agravada por mediar violencia } \\
0 \text { amenazas (art. } 144 \text { bis - inc. } 1^{\circ} \text { - y último párrafo -ley } \\
\text { 14.616-, en función del art. } 142 \text {-inc. } 1^{\circ} \text { - ley } 20.642 \text { ambos } \\
\text { del C.P.)" }\end{array}$ & $11 / 09 / 17$ & $\begin{array}{l}\text { Tribunal Oral Federal } 1 \\
\text { - Ciudad Autónoma de } \\
\text { Buenos Aires }\end{array}$ & Genocidio & Genocidio & $\begin{array}{l}\text { AUTOMOTORES } \\
\text { ORLETTI o EL } \\
\text { JARDÍN u OT } 18 \\
\text { (CABA) / } \\
\text { Automotores Orletti } \\
\quad \text { III y IV }\end{array}$ \\
\hline $\begin{array}{l}\text { "GONZÁLEZ CHIPONT, JULIO GUILLERMO Y OTROS } \\
\text { S/ PRIVACIÓN ILEGAL DE LIBERTAD (ART.144 BIS } \\
\text { INC.1) (LESA HUMANIDAD)" }\end{array}$ & $04 / 10 / 17$ & $\begin{array}{c}\text { Tribunal Oral Federal - } \\
\text { Bahía Blanca }\end{array}$ & Genocidio & Genocidio & $\begin{array}{c}\text { ESCUELITA DE } \\
\text { BAHÍA BLANCA } \\
\text { (BUENOS AIRES), } \\
\text { Batallón de } \\
\text { Comunicaciones 181, } \\
\text { Unidad Penal N44 } \\
\text { Villa Floresta, } \\
\text { Delegación } \\
\text { Cuatrerismo Bahía } \\
\text { Blanca, Delegación } \\
\text { Viedma } \\
\text { de la Policía Federal } \\
\text { Argentina / Tribunal } \\
\text { Oral Federal - Bahía } \\
\text { Blanca }\end{array}$ \\
\hline $\begin{array}{l}\text { "MENÉNDEZ SÁNCHEZ LUCIANO BENJAMÍN Y } \\
\text { OTROS S/ PRIVACIÓN ILEGITIMA DE LA LIBERTAD } \\
\text { (ART. } 144 \text { BIS INC. 1) E IMPOSICION DE TORMENTOS } \\
\text { (ART. } 144 \text { TER CP)". }\end{array}$ & $22 / 12 / 17$ & $\begin{array}{l}\text { Tribunal Oral Federal } \\
\mathrm{N}^{0} 2 \text { - Mendoza }\end{array}$ & Genocidio & Genocidio & Megacausa San Rafael \\
\hline $\begin{array}{l}\text { "MENÉNDEZ SÁNCHEZ LUCIANO BENJAMÍN Y } \\
\text { OTROS S/ PRIVACIÓN ILEGITIMA DE LA LIBERTAD } \\
\text { (ART. } 144 \text { BIS INC. 1) E IMPOSICION DE TORMENTOS } \\
\text { (ART. } 144 \text { TER CP)" }\end{array}$ & $22 / 12 / 17$ & $\begin{array}{l}\text { Tribunal Oral Federal } \\
\mathrm{N}^{0} \text { 2-Mendoza }\end{array}$ & Genocidio & Genocidio & $\begin{array}{l}\text { Casa Departamental } \\
\text { "Tribunales" / idem }\end{array}$ \\
\hline 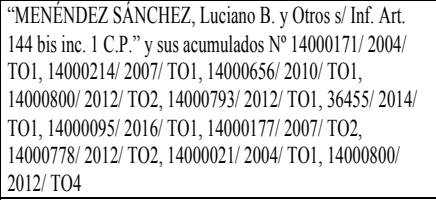 & $22 / 11 / 18$ & $\begin{array}{c}\text { Tribunal Oral Federal } 1 \\
\text { - Mendoza }\end{array}$ & Genocidio & Genocidio & $\begin{array}{l}\text { CAMPO LAS LAJAS } \\
\text { (MENDOZA)/ } \\
\text { Megacausa Mendoza } \\
\text { II }\end{array}$ \\
\hline $\begin{array}{l}\text { "Carabajal, Segundo Héctor y otros s/infr. art. } 146 \text { CP según } \\
\text { ley } 24.410 \text {, supresión del estado civil de un menor (art. } 139 \\
\text { inc. } 2 \text { CP según texto original ley } 11.179 \text { ), falsedad } \\
\text { ideológica conforme art. } 292 \text { último párrafo y uso de } \\
\text { documento adulterado o falso (art. } 296 \text { CP)" }\end{array}$ & $07 / 03 / 19$ & $\begin{array}{c}\text { Tribunal Oral Federal } 1 \\
\text { - Mendoza }\end{array}$ & Genocidio & Genocidio & $\begin{array}{l}\text { DEPARTAMENTO } \\
\text { DE } \\
\text { INFORMACIONES } \\
\text { DE LA POLICIAA DE } \\
\text { MENDOZA (D-2) } \\
\text { o JEFATURA DE } \\
\text { POLICÍA DE } \\
\text { MENDOZA } \\
\text { (MENDOZA) / idem }\end{array}$ \\
\hline
\end{tabular}

Fuente: elaborado sobre datos disponibles en http://crimenesdeestado.untref.edu.ar/busqueda-avanzada 